\title{
The econometrics of DSGE models
}

\author{
Jesús Fernández-Villaverde
}

Received: 24 January 2009 / Accepted: 22 October 2009 / Published online: 19 February 2010

(C) The Author(s) 2010. This article is published with open access at Springerlink.com

\begin{abstract}
In this paper, I review the literature on the formulation and estimation of dynamic stochastic general equilibrium (DSGE) models with a special emphasis on Bayesian methods. First, I discuss the evolution of DSGE models over the last couple of decades. Second, I explain why the profession has decided to estimate these models using Bayesian methods. Third, I briefly introduce some of the techniques required to compute and estimate these models. Fourth, I illustrate the techniques under consideration by estimating a benchmark DSGE model with real and nominal rigidities. I conclude by offering some pointers for future research.
\end{abstract}

Keywords DSGE models · Likelihood estimation · Bayesian methods

JEL Classification $\mathrm{C} 11 \cdot \mathrm{C} 13 \cdot \mathrm{E} 30$

\section{Introduction}

This article elaborates on a basic thesis: the formal estimation of dynamic stochastic general equilibrium (DSGE) models has become one of the cornerstones of modern macroeconomics. The combination of rich structural models, novel solution algorithms, and powerful simulation techniques has allowed researchers to transform the quantitative implementation of equilibrium models from a disparate collection

\footnotetext{
J. Fernández-Villaverde $(\varangle)$

University of Pennsylvania, Philadelphia, PA, USA

e-mail: jesusfv@econ.upenn.edu

J. Fernández-Villaverde

NBER, Cambridge, MA, USA

J. Fernández-Villaverde

CEPR, London, UK
} 
of ad hoc procedures to a systematic discipline where progress is fast and prospects entrancing. This captivating area of research, which for lack of a better name I call the New Macroeconometrics, is changing the way we think about models and about economic policy advice.

In the next pages, I will lay out my case in detail. I will start by framing the appearance of DSGE models in the context of the evolution of contemporary macroeconomics and how economists have reacted to incorporate both theoretical insights and empirical challenges. Then, I will explain why the New Macroeconometrics mainly follows a Bayesian approach. I will introduce some of the new techniques in the literature. I will illustrate these points with a benchmark application and I will conclude with a discussion of where I see the research at the frontier of macroeconometrics. Because of space limitations, I will not survey the field in exhausting detail or provide a complete description of the tools involved (indeed, I will offer the biased recommendation of many of my own papers). Instead, I will offer an entry point to the topic that, like the proverbial Wittgenstein's ladder, can eventually be discarded without undue apprehension once the reader has mastered the ideas considered here. The interested economist can also find alternative material on An and Schorfheide (2006), who focus more than I do on Bayesian techniques and less in pure macroeconomics, and in Fernández-Villaverde et al. (2008), where the work is related with general issues in Bayesian statistics, and in the recent textbooks on macroeconometrics by Canova (2007) and DeJong and Dave (2007).

\section{The main thesis}

Dynamic equilibrium theory made a quantum leap between the early 1970s and the late 1990s. In the comparatively brief space of 30 years, macroeconomists went from writing prototype models of rational expectations (think of Lucas 1972) to handling complex constructions like the economy in Christiano et al. (2005). It was similar to jumping from the Wright brothers to an Airbus 380 in one generation.

A particular keystone for that development was, of course, Kydland and Prescott (1982) paper Time to Build and Aggregate Fluctuations. For the first time, macroeconomists had a small and coherent dynamic model of the economy, built from first principles with optimizing agents, rational expectations, and market clearing, that could generate data that resembled observed variables to a remarkable degree. Yes, there were many dimensions along which the model failed, from the volatility of hours to the persistence of output. But the amazing feature was how well the model did despite having so little of what was traditionally thought of as the necessary ingredients of business cycle theories: money, nominal rigidities, or non-market clearing.

Except for a small but dedicated group of followers at Minnesota, Rochester, and other bastions of heresy, the initial reaction to Kydland and Prescott's assertions varied from amused incredulity to straightforward dismissal. The critics were either appalled by the whole idea that technological shocks could account for a substantial fraction of output volatility or infuriated by what they considered the superfluity of technical fireworks. After all, could we not have done the same in a model with two periods? What was so important about computing the whole equilibrium path of the economy? 
It turns out that while the first objection regarding the plausibility of technological shocks is alive and haunting us (even today the most sophisticated DSGE models still require a notable role for technological shocks, which can be seen as a good or a bad thing depending on your perspective), the second complaint has aged rapidly. As Max Plank remarked somewhere, a new methodology does not triumph by convincing its opponents, but rather because critics die and a new generation grows up that is familiar with it. ${ }^{1}$ Few occasions demonstrate the insight of Plank's witticism better than the spread of DSGE models. The new cohorts of graduate students quickly became acquainted with the new tools employed by Kydland and Prescott, such as recursive methods and computation, if only because of the comparative advantage that the mastery of technical material offers to young, ambitious minds. ${ }^{2}$ And naturally, in the process, younger researchers began to appreciate the flexibility offered by the tools. Once you know how to write down a value function in a model with complete markets and fully flexible prices, introducing rigidities or other market imperfections is only one step ahead: one more state variable here or there and you have a job market paper.

Obviously, I did not mention rigidities as a random example of contraptions that we include in our models, but to direct our attention to how surprisingly popular such additions to the main model turned out to be. Most macroeconomists, myself included, have always had a soft spot for nominal or real rigidities. A cynic will claim it is just because they are most convenient. After all, they dispense with the necessity for reflection, since there is hardly any observation of the aggregate behavior of the economy cannot be blamed on one rigidity or another. ${ }^{3}$

But just because a theory is inordinately serviceable or warrants the more serious accusation that it encourages mental laziness is certainly not proof that the theory is not true. At least since David Hume, economists have believed that they have identified a monetary transmission mechanism from increases in money to short-run fluctuations caused by some form or another of price stickiness. It takes much courage, and more aplomb, to dismiss two and a half centuries of a tradition linking Hume to Woodford and going through Marshall, Keynes, and Friedman. Even those with less of a Burkean mind than mine should feel reluctant to proceed in such a perilous manner. Moreover, after one finishes reading Friedman and Schwartz (1971) A Monetary History of the U.S. or slogging through the mountain of Vector Autoregressions (VARs) estimated over 25 years, it must be admitted that those who see money as an important factor in business cycles fluctuations have an impressive empirical case to rely on. Here is not the place to evaluate all these claims (although in the interest of disclosure, I must admit that I am myself less than totally convinced of the importance of money outside the case of large inflations). Suffice it to say that the previous arguments of intellectual tradition and data were a motivation compelling enough for the large number of

\footnotetext{
1 Admittedly, Plank talked about scientific truths and not methodologies, but the original incarnation sounds too outmodedly positivist for the contemporary foucaultian spirit.

2 Galesons's (2007) insights about the two types of artistic creativity and their life cycles are bound to apply to researchers as well.

3 A more sophisticated critic will even point out that the presence of rigidities at the micro level may wash out at an aggregate level, as in the wonderful example of Caplin and Spulber (1987).
} 
economists who jumped into the possibility of combining the beauty of DSGE models with the importance of money documented by empirical studies.

Researchers quickly found that we basically require three elements for that purpose. First, we need monopolistic competition. Without market power, any firm that does not immediately adjust its prices will lose all its sales. While monopolistic competition can be incorporated in different ways, the favorite route is to embody the DixitStiglitz framework into a general equilibrium environment, as so beautifully done by Blanchard and Kiyotaki (1987). While not totally satisfactory (for example, the basic Dixit-Stiglitz setup implies counterfactually constant mark-ups), the framework has proven to be easy to handle and surprisingly flexible. Second, we need some role to justify the existence of money. Money in the utility function or a cash-in-advance constraint can accomplish that goal in a not particularly elegant but rather effective way. ${ }^{4}$ Third, we need a monetary authority inducing nominal shocks to the economy. A monetary policy rule, such as a money growth process or a Taylor rule, usually nicely stands in for such authority. There were, in addition, two extra elements that improve the fit of the model. First, to delay and extend the response of the economy to shocks, macroeconomists postulated factors such as habit persistence in consumption, adjustment cost of investment, or a changing utilization rate of capital. Finally, many extra shocks were added: to investment, to preferences, to monetary and fiscal policy, etc. $^{5}$

The stochastic neoclassical growth model of Kydland and Prescott showed a remarkable ability to absorb all these mechanisms. After a transitional period of amalgamation during the 1990s, by 2003, the model augmented with nominal and real rigidities was sufficiently mature as to be put in a textbook by Woodford (2003) and to become the basis for applied work. For the first time, DSGE models were sufficiently flexible to fit the data sufficiently well as to be competitive with VARs in terms of forecasting power (see Edge et al. 2009, for the enchantingly good forecast record of a state-of-the-art DSGE model) and rich enough to become laboratories where realistic economic policies could be evaluated. The rest of the history is simple: DSGE models quickly became the standard tool for quantitative analysis of policies and every self-respecting central bank felt that it needed to estimate its own DSGE model. ${ }^{6}$ However, as surprising as the quick acceptance of DSGE models outside academic circles was, even more unexpected was the fact that models were not only formally estimated,

\footnotetext{
4 Wallace (2001) has listed many reasons to suspect that these mechanisms may miss important channels through which money matters. After all, they are reduced forms of an underlying model and, as such, they may not be invariant to policy changes. Unfortunately, the profession has not developed a well-founded model of money that can be taken to the data and applied to policy analysis. Despite some recent promising progress (Lagos and Wright 2005), money in the utility function or cash-in-advance will be with us for many years to come.

5 Also, researchers learned that it was easy to incorporate home production (Benhabib et al. 1991), an open-economy sector (Mendoza 1991, 1995; Backus et al. 1992, 1995; Correia et al. 1995) or a financial sector (Bernanke et al. 1999) among other extensions that I cannot discuss here.

6 Examples include the Federal Reserve Board (Erceg et al. 2006), the European Central Bank (ECB) (Christoffel et al. 2007), the Bank of Canada (Murchison and Rennison 2006), the Bank of England (Harrison et al. 2005), the Bank of Sweden (Adolfson et al. 2005), the Bank of Finland (Kilponen and Ripatti 2006; Kortelainen 2002), and the Bank of Spain (Andrés et al. 2006).
} 
leaving behind the rather unsatisfactory calibration approach, but they were estimated from a Bayesian perspective.

\section{The Bayesian approach}

I took my first course in Bayesian econometrics from John Geweke at the University of Minnesota in the fall of 1996. I remember how, during one of the lectures in that course, Geweke forecasted that in a few years, we would see a considerable proportion of papers in applied macro being written from a Bayesian perspective. I was rather skeptical about the prediction and dismissed Geweke's claim as an overly optimistic assessment by a committed Bayesian. Fortunately, Geweke was right and I was wrong. The last decade has indeed experienced an explosion of research using Bayesian methods; so much so that, during a recent talk, when I was presenting an estimation that for several reasons I had done using maximum likelihood, I was assailed by repeated instances of the question: why did not you use Bayes?, a predicament rather unimaginable even a decade ago.

How did such a remarkable change come about? It would be tempting to re-enumerate, as has been done innumerable times before, the long list of theoretical advantages of Bayesian statistics and state that it was only a matter of time before economists would accept the obvious superiority of the Bayes choice. In fact, I will momentarily punish the reader with yet one more review of some of those advantages, just to be sure that we are all on board. But the simpler truth is that, suddenly, doing Bayesian econometrics was easier than doing maximum likelihood. ${ }^{7}$

The reason is that maximizing a complicated, highly dimensional function like the likelihood of a DSGE model is actually much harder than it is to integrate it, which is what we do in a Bayesian exercise. First, the likelihood of DSGE models is, as I have just mentioned, a highly dimensional object, with a dozen or so parameters in the simplest cases to close to a hundred in some of the richest models in the literature. Any search in a high dimensional function is fraught with peril. More pointedly, likelihoods of DSGE models are full of local maxima and minima and of nearly flat surfaces. This is due both to the sparsity of the data (quarterly data do not give us the luxury of many observations that micro panels provide) and to the flexibility of DSGE models in generating similar behavior with relatively different combination of parameter values (every time you see a sensitivity analysis claiming that the results of the paper are robust to changes in parameter values, think about flat likelihoods). Consequently, even sophisticated maximization algorithms like simulated annealing or the simplex method run into serious difficulties when maximizing the likelihoods of dynamic models. Moreover, the standard errors of the estimates are notoriously difficult to compute and their asymptotic distribution a poor approximation to the small sample one.

\footnotetext{
7 This revival of Bayesian tools is by no means limited to econometrics. Bayesian methods have become extremely popular in many fields, such as genetics, cognitive science, weather analysis, and computer science. The forthcoming Handbook of Applied Bayesian Analysis edited by O'Hagan and West (2009) is a good survey of Bayesian statistics across many different disciplines.
} 
In comparison, Markov chain Monte Carlo (McMc) methods have a much easier time exploring the likelihood (more precisely, the likelihood times the prior) of DSGE models and offer a thorough view of our object of interest. That is why we may want to use McMc methods even when dealing with classical problems. Chernozhukov and Hong (2003) is a path-breaking paper that brought that possibility to the attention of the profession. Even more relevantly, McMc can be transported from application to application with a relatively small degree of fine tuning, an attractive property since the comparative advantage of most economists is not in numerical analysis (and, one suspects, neither their absolute advantage).

I promised before, though, that before entering into a more detailed description of techniques like McMc, I would inflict upon the reader yet another enumeration of the advantages of Bayesian thinking. But fortunately, this will be, given the circumstances of this paper, a rather short introduction. A whole textbook treatment of Bayesian statistics can be found in several excellent books in the market, among which I will recommend Robert (2001) and Bernardo and Smith (2000).

I start with a point that Chris Sims repeatedly makes in his talks: Bayesian inference is a way of thinking, not a "basket" of methods. Classical statistics searches for procedures that work well ex ante, i.e., procedures that applied in a repeated number of samples will deliver the right answer in a prespecified percentage of cases. This prescription is not, however, a constructive recipe. It tells us a property of the procedure we want to build and not how to do it. Consequently, we can come up with a large list of procedures that achieve the same objective without a clear metric to pick among them. The best possible illustration is the large number of tests that can be defined to evaluate the null hypothesis of cointegration of two random variables, each with its strengths and weaknesses. Furthermore, the procedures may be quite different in their philosophy and interpretation. In comparison, Bayesian inference is summarized in one simple idea: the Bayes' theorem. Instead of spending our time proving yet one more asymptotic distribution of a novel estimator, we can go directly to the data, apply Bayes' theorem, and learn from it. As simple as that.

Let me outline the elements that appear in the theorem. First, we have some data $y^{T} \equiv\left\{y_{t}\right\}_{t=1}^{T} \in \mathbb{R}^{N \times T}$. For simplicity, I will use an index $t$ that is more natural in a time series context like the one I will use below, but minimum work would adapt the notation to cross-sections or panels. From the Bayesian perspective, data are always given and, in most contexts, it does not make much sense to think about it as the realization of some data-generating process (except, perhaps when exploring some asymptotic properties of Bayesian methods as in Phillips and Ploberger 1996; Phillips 1996; Kim 1998; Fernández-Villaverde and Rubio-Ramírez 2004 among others). Second, we have a model, motivated either by economic theory or some other type of reasoning. The model is indexed by $i$ and it may be an instance of a set of possible models to consider $M$, i.e., we have $i \in M$. The model is composed by:

1. A parameter set, $\Theta_{i} \in \mathbb{R}^{k_{i}}$, that defines the admissible value of the parameters that index the functions in the model. Some restrictions come from statistics. For instance, variances must be positive. Others come from economic reasoning. For example, it is common to bound the discount factor in an intertemporal choice problem to ensure that total utility is well defined. 
2. A likelihood function $p\left(y^{T} \mid \theta, i\right): \mathbb{R}^{N \times T} \times \Theta_{i} \rightarrow \mathbb{R}^{+}$that tells us the probability that the model assigns to each observation given some parameter values. This likelihood function is nothing more than the restrictions that our model imposes on the data, either coming from statistical considerations or from equilibrium conditions.

3. A prior distribution $\pi(\theta \mid i): \Theta_{i} \rightarrow R^{+}$that captures pre-sample beliefs about the right value of the parameters (yes, "right" is an awfully ambiguous word; I will come back later to what I mean by it).

Bayes' theorem tells us that the posterior distribution of the parameters is given by:

$$
\pi\left(\theta \mid y^{T}, i\right)=\frac{p\left(y^{T} \mid \theta, i\right) \pi(\theta \mid i)}{\int p\left(y^{T} \mid \theta, i\right) \pi(\theta \mid i) d \theta} .
$$

This result, which follows from a basic application of the laws of probability, tells us how we should update our beliefs about parameter values: we combine our prior beliefs, $\pi(\theta \mid i)$, with the sample information embodied in the likelihood, $f\left(y^{T} \mid \theta, i\right)$, and we obtain a new set of beliefs, $\pi\left(\theta \mid y^{T}, i\right)$. In fact, Bayes' theorem is an optimal information processing rule as defined by Zellner (1988): it uses efficiently all of the available information in the data, both in small and large samples, without adding any extraneous information.

Armed with Bayes' theorem, a researcher does not need many more tools. For any possible model, one just writes down the likelihood, elicits the prior, and obtains the posterior. Once we have the posterior distribution of the parameters, we can perform inference like point estimation or model comparison given a loss function that maps how much we select an incorrect parameter value or model. For sure, these tasks can be onerous in terms of implementation but, conceptually, they are straightforward. Consequently, issues such as non-stationarity do not require specific methods as needed in classical inference (see the eye-opening helicopter tour of Sims and Uhlig 1991). If we suspect non-stationarities, we may want to change our priors to reflect that belief, but the likelihood function will still be the same and Bayes' theorem is applicable without the disconcerting discontinuities of classical procedures around the unit root.

But while coherence is certainly an attractive property, at least from an esthetic consideration, it is not enough by itself. A much more relevant point is that coherence is a consequence of the fact that Bayes' theorem can be derived from a set of axioms that decision theorists have proposed to characterize rational behavior. It is not an accident that the main solution concepts in games with incomplete information are Bayesian Nash equilibria and sequential equilibria and that Bayes' theorem plays a critical role in the construction of these solution concepts. It is ironic that we constantly see papers where the researcher specifies that the rational agents in the model follow Bayes' theorem and, then, she proceeds to estimate the model using classical procedures, undaunted by the implied logical contradiction.

Closely related to this point is the fact that the Bayesian approach satisfies by construction the Likelihood Principle (Berger and Wolpert 1988) that states that all of the information existing in a sample is contained in the likelihood function. Once one learns about how Birnbaum (1962) derived the Likelihood Principle from more fundamental axioms, it is rather difficult not to accept it. 
The advantages of Bayesian inference do not end here. First, Bayesian econometrics offers a set of answers that are relevant for users. In comparison, pre-sample probability statements are, on most occasions, rather uninteresting from a practical perspective. Few policy makers will be very excited if we inform them that in 95 of 100 possible samples, our model measures that a certain policy increases welfare but that we cannot really know if the actual data represents one of the 95 positive cases or one of the negative 5. They want to know, conditional on what we have observed in the data, what is the probability that we would be doing the right thing by, for instance, lowering the interest rate. A compelling proof of how unnatural it is to think in frequentist terms is to teach introductory statistics. Nearly all students will interpret confidence intervals at first as a probability interval. Only the repeated insistence of the instructor will make a disappointingly small minority of students understand the difference between the two and provide the right interpretation. The rest of the students, of course, would simply memorize the answer for the test in the same way they would memorize a sentence in Aramaic if such a worthless accomplishment were useful to get a passing grade. Neither policy makers nor undergraduate students are silly (they are ignorant, but that is a very different sin); they just think in ways that are more natural to humans. ${ }^{8}$ Frequentist statements are beautiful but inconsequential.

Second, pre-sample information is often amazingly rich and considerably useful and not taking advantage of it is an unforgivable omission. For instance, microeconometric evidence can guide our building of priors. If we have a substantial set of studies that estimate the discount factor of individuals and they find a range of values between 0.9 and 0.99 , any sensible prior should take this information into consideration.

The researcher should be careful, though, translating this micro evidence into macro priors. Parameter values do not have an existence of their own, like a Platonic entity waiting to be discovered. They are only defined within the context of a model, and changes in the theory, even if minor, may have a considerable impact on the parameter values. A paradigmatic example is labor supply. For a long time, labor economists criticized the real business cycle models because they relied on what they saw as an unreasonably high labor supply elasticity (Alesina et al. 2006, is a recent instance of such criticism). However, the evidence that fed their attacks was gathered mainly for prime age white males in the United States (or a similarly restrictive group). But representative agent models are not about prime age white males: the representative agent is instead a stand-in for everyone in the economy. It has a bit of a prime age male and a bit of old woman, a bit of a minority young and a bit of a part-timer. If much of the response of labor to changes in wages is done through the labor supply of women and young workers, it is perfectly possible to have a high aggregate elasticity of labor supply and a low labor supply elasticity of prime age males. To illustrate this point, Rogerson and Wallenius (2007) construct an overlapping generations economy where the micro and macro elasticities are virtually unrelated. But we should not push the previous example to an exaggerated degree: it is a word of caution, not a licence to concoct wild priors. If the researcher wants to depart in her prior from the micro estimates, she must have at least some plausible explanation of why she is doing so

\footnotetext{
${ }^{8}$ See also the psychological evidence that humans' cognitive processes are well described by Bayes' theorem presented by Griffiths and Tenenbaum (2006).
} 
(see Browning et al. 1999 for a thorough discussion of the mapping between micro and macro estimates).

An alternative source of pre-sample information is the estimates of macro parameters from different countries. One of the main differences between economists and other social scientists is that we have a default belief that individuals are basically the same across countries and that differences in behavior can be accounted for by differences in relative prices. Therefore, if we have estimates from Germany that the discount factor in a DSGE model is around 0.98, it is perfectly reasonable to believe that the discount factor in Spain, if we estimate the same model, should be around 0.98. Admittedly, differences in demographics or financial markets may show up as slightly different discount factors, but again, the German experience is most informative. Pre-sample information is particularly convenient when we deal with emerging economies, when the data as extremely limited, or when we face a change in policy regime. A favorite example of mine concerns the creation of the ECB. If we were back in 1998 or 1999 trying to estimate a model of how the ECB works, we would face such a severe limitation in the length of the data that any classical method would fail miserably. However, we could have used a Bayesian method where the prior would have been that the ECB would behave in a way very similar than the German Bundesbank. Yes, our inference would have depended heavily on the prior, but why is this situation any worse than not being able to say anything of consequence? Real life is full of situations where data are extremely sparse (or where they speak to us very softly about the difference between two models, like a unit root process and an AR(1) with coefficient 0.99 ) and we need to make the best of a bad situation by carefully eliciting priors. ${ }^{9}$

Third, Bayesian econometrics allows a direct computation of many objects of interest, such as the posterior distribution of welfare gains, values at risk, fan charts, and many other complicated functions of the underlaying parameters while capturing in these computed objects all the existing uncertainty regarding parameter values. For example, instead of computing the multiplier of an increase in public consumption (per se, not a very useful number for a politician), we can find the whole posterior distribution of employment changes in the next year conditioning on what we know about the evolution of the economy plus the effect of an increase in public consumption. Such an object, with its whole assessment of risks, is a much more relevant tool for policy analysis. Classical procedures have a much more difficult time jumping from point estimates to whole distributions of policy-relevant objects.

Finally, Bayesian econometrics deals in a natural way with misspecified models (Monfort 1996). As the old saying goes, all models are false, but some are useful. Bayesians are not in the business of searching for the truth but only in coming up with good description of the data. Hence, estimation moves away from being a process of discov-

\footnotetext{
9 We can push the arguments to the limit. Strictly speaking we can perform Bayesian inference without any data: our posterior is just equal to the prior! We often face this situation. Imagine that we were back in 1917 and we just heard about the Russian revolution. Since communism had never been tried, as economists we would need to endorse or reject the new economic system exclusively based on our priors about how well central planning could work. Waiting 70 years to see how well the whole experiment would work is not a reasonable course of action.
} 
ery of some "true" value of a parameter to being, in Rissanen (1986) powerful words, a selection device in the parameter space that maximizes our ability to use the model as a language in which to express the regular features of the data. Coming back to our previous discussion about "right" parameters, Rissanen is telling us to pick those parameter values that allow us to tell powerful economic histories and to exert control over outcomes of interest. These parameter values, which I will call "pseudotrue," may be, for example, the ones that minimize the Kullback-Leibler distance between the data generating process and the model (Fernández-Villaverde and Rubio-Ramírez 2004, offer a detailed explanation of why we care about these "pseudotrue" parameter values).

Also, by thinking about models and parameters in this way, we come to the discussion of partially identified models initiated by Manski (1999) from a different perspective. Bayesians emphasize more the "normality" of a lack of identification than the problems caused by it. Bayesians can still perform all of their work without further complications or the need of new theorems even with a flat posterior (and we can always achieve identification through non-flat priors, although such an accomplishment is slightly boring). For example, I can still perfectly evaluate the welfare consequences of one action if the posterior of my parameter values is flat in some or all of the parameter space. The answer I get may have a large degree of uncertainty, but there is nothing conceptually different about the inference process. This does not imply, of course, that identification is not a concern. ${ }^{10}$ I only mean that identification is a somehow different preoccupation for a Bayesian.

I would not be fully honest, however, if I did not discuss, if only briefly, the disadvantages of Bayesian inference. The main one, in my opinion, is that many non-parametric and semiparametric approaches sound more natural when set up in a classical framework. Think about the case of the Generalized Method of Moments (GMM). The first time you hear about it in class, your brain (or at least mine!) goes "ah!, this makes perfect sense." And it does so because GMM (and all its related cousins in the literature of empirical likelihood, Owen 2001, and, in economics, Kitamura and Stutzer 1997) are clear and intuitive procedures that have a transparent and direct link with first order conditions and equilibrium equations. Also, methods of moments are a good way to estimate models with multiple equilibria, since all of those equilibria need to satisfy certain first order conditions that we can exploit to come up with a set of moments. ${ }^{11}$ Even if you can cook up many things in a Bayesian framework that look a lot like GMM or empirical likelihood (see, for example, Kim 1998; Schennach 2005, or Ragusa 2006, among several others), I have never been particularly satisfied with any of them and none has passed the "ah!" test that GMM overcomes with such an excellent grade.

Similarly, you can implement a non-parametric Bayesian analysis (see the textbook by Ghosh and Ramamoorthi 2003, and in economics, Chamberlain and Imbens 2003).

\footnotetext{
10 Identification issues ought to be discussed in more detail in DSGE models, since they affect the conclusions we get from them. See Canova and Sala (2006) for examples of non-identified DSGE models and further discussion, and Komunjer and $\mathrm{Ng}(2009 \mathrm{a}, \mathrm{b})$ for a careful statistical analysis using the theory of state space systems.

${ }^{11}$ A simple way to generate multiplicity of equilibria in a DSGE model that can be very relevant empirically is to have increasing returns to scale, as in Benhabib and Farmer (1992). For a macro perspective on estimation of models with multiplicity of equilibria, see Jovanovic (1989) or Cooper (2002).
} 
However, the methods are not as well developed as we would like and the shining building of Bayesian statistics gets dirty with some awful discoveries such as the potentially bad asymptotic properties of Bayesian estimators (first pointed out by Freedman 1963) or the breakdown of the likelihood principle (Robins and Ritov 1997). Given that the literature is rapidly evolving, Bayesian methods may end up catching up and even overcoming classical procedures for non-parametric and semiparametric problems, but this has not happened yet. In the meantime, the advantage in this sub-area seems to be in the frequentist camp.

\section{The tools}

No matter how sound were the DSGE models presented by the literature or how compelling the arguments for Bayesian inference, the whole research program would not have taken off without the appearance of the right set of tools that made the practical implementation of the estimation of DSGE models feasible in a standard desktop computer. Otherwise, we would probably still be calibrating our models, which would be, in addition, much smaller and simpler. I will classify those tools in three sets. First, better and improved solution methods. Second, methods to evaluate the likelihood of the model. Third, methods to explore the likelihood of the model.

\subsection{Solution methods}

DSGE models do not have, except for a very few exceptions, a "paper and pencil" solution. Hence, we are forced to resort to numerical approximations to characterize the equilibrium dynamics of the model. Numerical analysis is not part of the standard curriculum either at the undergraduate or the graduate level. Consequently, the profession had a tough time accepting that analytic results are limited (despite the fact that the limitations of close form findings happens in most other sciences where the transition to numerical approximations happened more thoroughly and with less soul searching). To make things worse, few economists were confident in dealing with the solution of stochastic difference functional equations, which are the core of the solution of a DSGE model. The first approaches were based on fitting the models to be solved into the framework of what was described in standard optimal control literature textbooks. For example, Kydland and Prescott (1982) substituted the original problem by a linear quadratic approximation to it. King et al. (2002) (in the widely disseminated technical appendix, not published until 2002) linearized the equilibrium conditions, and Christiano (1990) applied value function iteration. Even if those approaches are still the cornerstone of much of what is done nowadays, as time passed, researchers became familiar with them, many improvements were proposed, and software circulated.

Let me use the example of linearization, since it is the solution method that I will use below. ${ }^{12}$ Judd and Guu (1993) showed that linearization was not an ad hoc

\footnotetext{
12 Other solution methods for DSGE models, such as projection algorithms and value function iteration, are described and compared in Aruoba et al. (2006). Judd (1998) is a comprehensive textbook.
} 
procedure but the first order term of a mainstream tool in scientific computation, perturbation. The idea of perturbation methods is to substitute the original problem, which is difficult to solve, for a simpler one that we know how to handle and use the solution of the simpler model to approximate the solution of the problem we are interested in. In the case of DSGE models, we find an approximated solution by finding a Taylor expansion of the policy function describing the dynamics of the variables of the model around the deterministic steady state. Linearization, therefore, is just the first term of this Taylor expansion. But once we understand this, it is straightforward to get higher order expansions that are both analytically informative and more accurate (as in Schmitt-Grohé and Uribe 2004). ${ }^{13}$ Similarly, we can apply all of the accumulated knowledge of perturbation methods in terms of theorems or in improving the performance of the method. ${ }^{14}$ Second, once economists became more experienced with linearization, software disseminated very quickly.

My favorite example is Dynare and Dynare++, an extraordinary tool developed by Michel Juillard and a team of collaborators. Dynare (a toolbox for Matlab and Scilab) and Dynare++ (a stand-alone application) allow the researcher to write, in a concise and intuitive language, the equilibrium conditions of a DSGE model and find a perturbation solution to it, up to second order in Dynare and to an arbitrary order in Dynare++. With Dynare and Dynare++, a moderately experienced user can write code for a basic real business cycle model in an hour and compute the approximated solution in a few seconds. The computation of the model presented below (a fairly sophisticated one) requires a bit more effort, but still coding can be done in a short period of time (as short as a day or two for an experienced user) and the solution and simulation take only a few seconds. This advance in the ease of computation is nothing short of breathtaking.

\subsection{Evaluating the likelihood function}

In our previous description of Bayes' theorem, the likelihood function of the model played a key role, since it was the object that we multiplied by our prior to obtain a posterior. The challenge is how to obtain the likelihood of a DSGE model for which

\footnotetext{
13 For example, a second order expansion includes a term that corrects for the standard deviation of the shocks that drive the dynamics of the economy. This term, which captures precautionary behavior, breaks the certainty equivalence of linear approximations that makes it difficult to talk about welfare and risk.

14 Here I can cite the idea of changing variables (Fernández-Villaverde and Rubio-Ramirez 2006). Instead of writing a Taylor expansion in terms of a variable $x$ :
}

$$
f(x) \simeq f(a)+f^{\prime}(a)(x-a)+H . O . T .,
$$

we can write it in terms of a transformed variable $Y(x)$ :

$$
g(y)=h(f(X(y)))=g(b)+g^{\prime}(b)(Y(x)-b)+\text { H.O.T. },
$$

where $b=Y(a)$ and $X(y)$ is the inverse of $Y(x)$. By picking the right change of variables, we can significantly increase the accuracy of the perturbation. A common example of change of variables (although rarely thought of in this way) is to loglinearize instead of linearizing in levels. 
we do not even have an analytic solution. The most general and powerful route is to employ the tools of state space representations and filtering theory.

Once we have the solution of the DSGE model in terms of its (approximated) policy functions, we can write the laws of motion of the variables in a state space representation $^{15}$ that consists of:

1. A transition equation, $S_{t}=f\left(S_{t-1}, W_{t} ; \theta\right)$, where $S_{t}$ is the vector of states that describe the situation of the model in any given moment in time, $W_{t}$ is a vector of innovations, and $\theta$ is a vector with the structural parameters that describe technology, preferences, and information processes.

2. A measurement equation, $Y_{t}=g\left(S_{t}, V_{t} ; \theta\right)$, where $Y_{t}$ are the observables and $V_{t}$ a set of shocks to the observables (like, but not necessarily, measurement errors).

While the transition equation is unique up to an equivalent class, the measurement equation depends on what we assume we can observe, selection that may imply many degrees of freedom. For example, we can assume that we observe wages or that we observe hours (or even that we have access to both series), since the model has predictions regarding both variables. The only restriction is that we can only select a number of series less than or equal to the number of shocks in the model ( $W_{t}$ and $\left.V_{t}\right)$. Otherwise, the model will be up to first order, stochastically singular, that is, the extra observables would be a deterministic functions of the other observables and the likelihood would be $-\infty$ with probability 1 , voiding any inference exercise. ${ }^{16}$

Unfortunately, this selection of variables may have important consequences for inference (see the experiments in Guerrón-Quintana 2008) and econometric theory has few tight rules for guidance. In general, the researcher should focus on the time series that she find particularly informative for her purposes, although doing so may require some exploration. For instance, it is reasonable to guess that, in a model centered on analyzing the labor market, data regarding hours, unemployment, and hours are particularly relevant while data on money velocity is not. As an alternative, Boivin and Giannoni (2006) opt for using large data sets, which avoids determining which variables we want to select for estimation, and relate them with the DSGE model with a flexible factor-style representation. However, this route may complicate identification, already a weak point of estimated DSGE models. ${ }^{17}$

The state space representation lends itself to many convenient computations. To begin with, from $S_{t}=f\left(S_{t-1}, W_{t} ; \theta\right)$, we can compute $p\left(S_{t} \mid S_{t-1} ; \theta\right)$, from $Y_{t}=g\left(S_{t}, V_{t} ; \theta\right)$, we can compute $p\left(Y_{t} \mid S_{t} ; \theta\right)$, and from $S_{t}=f\left(S_{t-1}, W_{t} ; \theta\right)$ and $Y_{t}=g\left(S_{t}, V_{t} ; \theta\right)$, we have:

\footnotetext{
15 Here, I am assuming that there exists a state space representation that is Markov in some vector of states. By admitting no-payoff relevant states, like Lagrangian multipliers that encode continuation utilities (Abreu et al. 1990), we can fit a large class of economic models into this setup.

16 While this restriction used to be binding, forcing researchers to add measurement errors, nowadays, DSGE models are usually sufficiently rich in terms of shocks to allow for many observables. If anything, the problem comes from the existence of too many shocks with a tenuous structural interpretation.

17 Boivin and Giannoni's approach has the extra advantage that we do not need to take a strong stand in the relation between observables such as GDP with output as defined by the model, a mapping that is always controversial as statistical agencies do not always follow the same criteria than the ones implied by our theory.
} 


$$
Y_{t}=g\left(f\left(S_{t-1}, W_{t} ; \theta\right), V_{t} ; \theta\right)
$$

and hence we can compute $p\left(Y_{t} \mid S_{t-1} ; \theta\right)$ (here I am omitting the technical details regarding the existence of these objects).

All of these conditional densities appear in the likelihood function in a slightly disguised way. If we want to evaluate the likelihood function of the observables $y^{T}$ at parameter values $\theta, p\left(y^{T} ; \theta\right)$, we can start by taking advantage of the Markov structure of our state space representation to write:

$$
\begin{aligned}
p\left(y^{T} \mid \theta\right) & =p\left(y_{1} \mid \theta\right) \prod_{t=2}^{T} p\left(y_{t} \mid y^{t-1} ; \theta\right) \\
& =\int p\left(y_{1} \mid s_{1} ; \theta\right) d S_{1} \prod_{t=2}^{T} \int p\left(y_{t} \mid S_{t} ; \theta\right) p\left(S_{t} \mid y^{t-1} ; \theta\right) d S_{t} .
\end{aligned}
$$

Hence, knowledge of $\left\{p\left(S_{t} \mid y^{t-1} ; \theta\right)\right\}_{t=1}^{T}$ and $p\left(S_{1} ; \theta\right)$ allow the evaluation of the likelihood of the model.

Filtering theory is the branch of mathematics that is preoccupied precisely with finding the sequence of conditional distributions of states given observations, $\left\{p\left(S_{t} \mid y^{t-1} ; \theta\right)\right\}_{t=1}^{T}$. For this task, it relies on two fundamental tools, the ChapmanKolmogorov equation:

$$
p\left(S_{t+1} \mid y^{t} ; \theta\right)=\int p\left(S_{t+1} \mid S_{t} ; \theta\right) p\left(S_{t} \mid y^{t} ; \theta\right) d S_{t}
$$

and Bayes' theorem (yes, again):

$$
p\left(S_{t} \mid y^{t} ; \theta\right)=\frac{p\left(y_{t} \mid S_{t} ; \theta\right) p\left(S_{t} \mid y^{t-1} ; \theta\right)}{p\left(y_{t} \mid y^{t-1} ; \theta\right)},
$$

where

$$
p\left(y_{t} \mid y^{t-1} ; \theta\right)=\int p\left(y_{t} \mid S_{t} ; \theta\right) p\left(S_{t} \mid y^{t-1} ; \theta\right) d S_{t}
$$

is the conditional likelihood.

The Chapman-Kolmogorov equation, despite its intimidating name, tells us only that the distribution of states tomorrow given an observation until today, $p\left(S_{t+1} \mid y^{t} ; \theta\right)$, is equal to the distribution today of $p\left(S_{t} \mid y^{t} ; \theta\right)$ times the transition probabilities $p\left(S_{t+1} \mid S_{t} ; \theta\right)$ integrated over all possible states. Therefore, the Chapman-Kolmogorov equation just gives us a forecasting rule for the evolution of states. Bayes' theorem updates the distribution of states $p\left(S_{t} \mid y^{t-1} ; \theta\right)$ when a new observation arrives given its probability $p\left(y_{t} \mid S_{t} ; \theta\right)$. By a recursive application of forecasting and updating, we can generate the complete sequence $\left\{p\left(S_{t} \mid y^{t-1} ; \theta\right)\right\}_{t=1}^{T}$ we are looking for.

While the Chapman-Kolmogorov equation and Bayes' theorem are mathematically rather straightforward objects, their practical implementation is cumbersome because 
they involve the computation of numerous integrals. Even when the number of states is moderate, the computational cost of these integrals makes an exact (or up to floating point accuracy) evaluation of the integrals unfeasible.

\subsubsection{The Kalman filter}

To fix this computational problem, we have two routes. First, if the transition and measurement equation are linear and the shocks are normally distributed, we can take advantage of the observation that all of the relevant conditional distributions are Gaussian (this just from the simple fact that the space of normal distributions is a vector space). Therefore, we only need to keep track of the mean and variance of these conditional normals. The tracking of the moments is done through the Ricatti equations of the Kalman filter (for more details, see any standard textbook, such as Harvey 1989, or Stengel 1994).

To do so, we start by writing the first order linear approximation to the solution of the model in the state space representation we introduced above:

$$
\begin{aligned}
s_{t} & =A s_{t-1}+B \varepsilon_{t}, \\
y_{t} & =C s_{t}+D \varepsilon_{t}, \\
\varepsilon_{t} & \sim \mathbf{N}(0, I),
\end{aligned}
$$

where we use lower case letters to denote realizations of the random variable and where $\varepsilon_{t}$ is the vector of innovations to the model that stacks $W_{t}$ and $V_{t}$.

Let us define the linear projections $s_{t \mid t-1}=\mathbb{E}\left(s_{t} \mid Y_{t-1}\right)$ and $s_{t \mid t}=\mathbb{E}\left(s_{t} \mid Y_{t}\right)$ where $Y_{t}=\left\{y_{1}, y_{2}, \ldots, y_{t}\right\}$ and the subindex tracks the conditioning set (i.e., $t \mid t-1$ means a draw at moment $t$ conditional on information until $t-1)$. Also, we have matrices of variances-covariances $P_{t-1 \mid t-1}=\mathbb{E}\left(s_{t-1}-s_{t-1 \mid t-1}\right)\left(s_{t-1}-s_{t-1 \mid t-1}\right)^{\prime}$ and $P_{t \mid t-1}=\mathbb{E}\left(s_{t-1}-s_{t \mid t-1}\right)\left(s_{t-1}-s_{t \mid t-1}\right)^{\prime}$. Given these linear projections and the Gaussian structure of our state space representations, the one-step-ahead forecast error, $\eta_{t}=y_{t}-C s_{t \mid t-1}$, is white noise.

We forecast the evolution of states:

$$
s_{t \mid t-1}=A s_{t-1 \mid t-1} .
$$

Since the possible presence of correlation in the innovations does not change the nature of the filter (Stengel 1994), so it is still the case that

$$
s_{t \mid t}=s_{t \mid t-1}+K \eta_{t},
$$

where $K$ is the Kalman gain at time $t$. Define variance of forecast as $V_{y}=C P_{t \mid t-1} C^{\prime}+$ $D D^{\prime}$.

Since $\eta_{t}$ is white noise, the conditional loglikelihood of the period observation $y_{t}$ is just:

$$
\log p\left(y_{t} \mid \theta\right)=-\frac{n}{2} \log 2 \pi-\frac{1}{2} \log \operatorname{det}\left(V_{y}\right)-\frac{1}{2} \eta_{t} V_{y}^{-1} \eta_{t}
$$


The last step is to update our estimates of the states. Define residuals $\xi_{t \mid t-1}=$ $s_{t}-s_{t \mid t-1}$ and $\xi_{t \mid t}=s_{t}-s_{t \mid t}$. Subtracting Eq. (3) from Eq. (1)

$$
\begin{aligned}
s_{t}-s_{t \mid x-1} & =A\left(s_{t-1}-s_{t-1 \mid t-1}\right)+B w_{t}, \\
\xi_{t \mid t-1} & =A \xi_{t-1 \mid t-1}+B w_{t} .
\end{aligned}
$$

Now subtract Eq. (4) from Eq. (1)

$$
\begin{aligned}
s_{t}-s_{t \mid t} & =s_{t}-s_{t \mid t-1}-K\left[C s_{t}+D w_{t}-C s_{t \mid t-1}\right], \\
\xi_{t \mid t} & =\xi_{t \mid t-1}-K\left[C \xi_{t \mid t-1}+D w_{t}\right] .
\end{aligned}
$$

Note $P_{t \mid t-1}$ can be written as

$$
\begin{aligned}
P_{t \mid t-1} & =\mathbb{E} \xi_{t \mid t-1} \xi_{t \mid t-1}^{\prime} \\
& =\mathbb{E}\left(A \xi_{t-1 \mid t-1}+B w_{t}\right)\left(A \xi_{t-1 \mid t-1}+B w_{t}\right)^{\prime} \\
& =A P_{t-1 \mid t-1} A^{\prime}+B B^{\prime}
\end{aligned}
$$

and for $P_{t \mid t}$ we have:

$$
\begin{aligned}
P_{t \mid t}= & \mathbb{E} \xi_{t \mid t} \xi_{t \mid t}^{\prime} \\
= & \mathbb{E}\left(\xi_{t \mid t-1}-K\left[C \xi_{t \mid t-1}+D w_{t}\right]\right)\left(\xi_{t \mid t-1}-K\left[C \xi_{t \mid t-1}+D w_{t}\right]\right)^{\prime} \\
= & (I-K C) P_{t \mid t-1}\left(I-C^{\prime} K^{\prime}\right)+K D D^{\prime} K^{\prime}-K D B^{\prime} \\
& -B D^{\prime} K^{\prime}+K C B D^{\prime} K^{\prime}+K D B^{\prime} C^{\prime} K^{\prime} .
\end{aligned}
$$

The optimal gain $K$ minimizes $P_{t \mid t}$ with the first order condition

$$
\frac{\partial \operatorname{Tr}\left(P_{t \mid t}\right)}{\partial K}=0
$$

and solution

$$
K=\left[P_{t \mid t-1} C^{\prime}+B D^{\prime}\right]\left[V_{y}+C B D^{\prime}+D B^{\prime} C^{\prime}\right]^{-1}
$$

Consequently, the updating equations are:

$$
\begin{aligned}
P_{t \mid t} & =P_{t \mid t-1}-K_{o p t}\left[D B^{\prime}+C P_{t \mid t-1}\right], \\
x_{t \mid t} & =x_{t \mid t-1}+K_{o p t} \eta_{t}
\end{aligned}
$$

and we close the iterations. We only need to apply the equations from $t=1$ until $T$ and we can compute the loglikelihood function. The whole process takes only a fraction of a second on a modern laptop computer. 


\subsubsection{The particle filter}

Unfortunately, linearity and Gaussanity are quite restrictive assumptions. For example, linearization eliminates asymmetries, threshold effects, precautionary behavior, big shocks, and many other phenomena of interest in macroeconomics. Moreover, linearization induces an approximation error. Even if we were able to evaluate the likelihood implied by that solution, we would not be evaluating the likelihood of the exact solution of the model but the likelihood implied by the approximated linear solution of the model. Both objects may be quite different and some care is required when we proceed to perform inference (for further details, see Fernández-Villaverde et al. 2006). The effects of this are worse than you may think. First, there are theoretical arguments. Second order errors in the approximated policy function may imply first order errors in the loglikelihood function. As the sample size grows, the error in the loglikelihood function also grows and we may have inconsistent point estimates. Second, linearization complicates the identification of parameters (or makes it plainly impossible as, for example, the coefficient of risk aversion in a model with EpsteinZin preferences as introduced by Epstein and Zin 1989, 1991). Finally, computational evidence suggests that those effects may be important in many applications.

Similarly Gaussanity eliminates the possibility of talking about time-varying volatility in time series, which is a fundamental issue in macroeconomics. For instance, McConnell and Pérez-Quirós (2000), Kim and Nelson (1998), Fernández-Villaverde and Rubio-Ramírez (2007), and Justiniano and Primiceri (2008) have accumulated rather compelling evidence of the importance of time-varying volatility to account for the dynamics of U.S. data. Any linear Gaussian model cannot talk about this evidence at all. Similarly, linear models cannot deal with models that display regime switching, an important feature of much recent research (see Sims and Zha 2006; Farmer et al. 2006a,b).

When the state space representation is not linear or when the shocks are not normal, filtering becomes more complicated because the conditional distributions of states do not belong, in general, to any known family. How do we keep track of them? We mentioned before that analytic methods are unfeasible except in a few cases. Therefore, we need to resort to some type of simulation. An algorithm that has been used recently with much success is the particle filter, a particular example of a Sequential Monte Carlo (see the technical appendix to Fernández-Villaverde and Rubio-Ramírez 2007 for alternative approaches).

Because of space constraints, I will not discuss the filter in much detail (FernándezVillaverde and Rubio-Ramírez 2005, 2007, provide all the technical background; see Arulampalam et al. 2002 for a general introduction, and Doucet et al. 2001, for a collection of applications). The main idea, however, is extremely simple: we replace the conditional distribution $\left\{p\left(S_{t} \mid y^{t-1} ; \theta\right)\right\}_{t=1}^{T}$ by an empirical distribution of $N$ draws $\left\{\left\{s_{t \mid t-1}^{i}\right\}_{i=1}^{N}\right\}_{t=1}^{T}$ from the sequence $\left\{p\left(S_{t} \mid y^{t-1} ; \theta\right)\right\}_{t=1}^{T}$ generated by simulation. Then, by a trivial application of the law of large numbers:

$$
p\left(y^{T} \mid \theta\right) \simeq \frac{1}{N} \sum_{i=1}^{N} p\left(y_{1} \mid s_{0 \mid 0}^{i} ; \theta\right) \prod_{t=2}^{T} \frac{1}{N} \sum_{i=1}^{N} p\left(y_{t} \mid s_{t \mid t-1}^{i} ; \theta\right) .
$$


The problem is then to draw from $\left\{p\left(S_{t} \mid y^{t-1} ; \theta\right)\right\}_{t=1}^{T}$. But, following Rubin (1988), we can apply sequential sampling:

Proposition 1 Let $\left\{s_{t \mid t-1}^{i}\right\}_{i=1}^{N}$ be a draw from $p\left(S_{t} \mid y^{t-1} ; \theta\right)$. Let the sequence $\left\{\tilde{s}_{t}^{i}\right\}_{i=1}^{N}$ be a draw with replacement from $\left\{s_{t \mid t-1}^{i}\right\}_{i=1}^{N}$ where the resampling probability is given by

$$
\omega_{t}^{i}=\frac{p\left(y_{t} \mid s_{t \mid t-1}^{i} ; \theta\right)}{\sum_{i=1}^{N} p\left(y_{t} \mid s_{t \mid t-1}^{i} ; \theta\right)}
$$

Then $\left\{\widetilde{s}_{t}^{i}\right\}_{i=1}^{N}$ is a draw from $p\left(S_{t} \mid y^{t} ; \theta\right)$.

Proposition 1 recursively uses a draw $\left\{s_{t \mid t-1}^{i}\right\}_{i=1}^{N}$ from $p\left(S_{t} \mid y^{t-1} ; \theta\right)$ to draw $\left\{s_{t \mid t}^{i}\right\}_{i=1}^{N}$ from $p\left(S_{t} \mid y^{t} ; \theta\right)$. But this is nothing more than the update of our estimate of $S_{t}$ to add the information on $y_{t}$ that Bayes' theorem is asking for.

The reader may be surprised by the need to resample to obtain a new conditional distribution. However, without resampling, all of the sequences would become arbitrarily far away from the true sequence of states and the sequence that is closer to the true states dominates all of the remaining ones in weight. Hence, the simulation degenerates after a few steps and we cannot effectively evaluate the likelihood function, no matter how large $N$ is.

Once we have $\left\{s_{t \mid t}^{i}\right\}_{i=1}^{N}$, we draw $N$ vectors of exogenous shocks to the model (for example, the productivity or the preference shocks) from their corresponding distributions and apply the law of motion for states to generate $\left\{s_{t+1 \mid t}^{i}\right\}_{i=1}^{N}$. This step, known as forecast, puts us back at the beginning of Proposition 1, but with the difference that we have moved forward one period in our conditioning, from $t \mid t-1$ to $t+1 \mid t$, implementing in that way the Chapman-Kolmogorov equation.

The following pseudo-code summarizes the description of the algorithm:

Step 0, Initialization: Set $t \rightsquigarrow 1$. Sample $N$ values $\left\{s_{0 \mid 0}^{i}\right\}_{i=1}^{N}$ from $p\left(S_{0} ; \theta\right)$.

Step 1, Prediction: Sample $N$ values $\left\{s_{t \mid t-1}^{i}\right\}_{i=1}^{N}$ using $\left\{s_{t-1 \mid t-1}^{i}\right\}_{i=1}^{N}$, the law of motion for states and the distribution of shocks $\varepsilon_{t}$.

Step 2, Filtering: Assign to each draw $\left(s_{t \mid t-1}^{i}\right)$ the weight $\omega_{t}^{i}$ in Proposition 1 .

Step 3, Sampling: Sample $N$ times with replacement from $\left\{s_{t \mid t-1}^{i}\right\}_{i=1}^{N}$ using the probabilities $\left\{\omega_{t}^{i}\right\}_{i=1}^{N}$. Call each draw $\left(s_{t \mid t}^{i}\right)$. If $t<T$ set $t \rightsquigarrow t+1$ and go to step 1. Otherwise stop. 
With the simulation, we just substitute into our formula

$$
p\left(y^{T} \mid \theta\right) \simeq \frac{1}{N} \sum_{i=1}^{N} p\left(y_{1} \mid s_{0 \mid 0}^{i} ; \Psi\right) \prod_{t=2}^{T} \frac{1}{N} \sum_{i=1}^{N} p\left(y_{t} \mid s_{t \mid t-1}^{i} ; \theta\right)
$$

and get an estimate of the likelihood of the model given $\theta$. Del Moral and Jacod (2002) and Künsch (2005) show weak conditions for the consistency of this estimator and for a central limit theorem to apply.

\subsection{Exploring the likelihood function}

Once we have an evaluation of the likelihood function from filtering theory, we need to explore it, either by maximization or by description. As I explained before when I motivated the Bayesian choice, maximization is particularly challenging and the results are often not very robust. Consequently, I will not get into a discussion of how we can attempt to solve this complicated optimization. The Bayesian alternative is, of course, to find the posterior:

$$
\pi\left(\theta \mid y^{T}\right)=\frac{p\left(y^{T} \mid \theta\right) \pi(\theta)}{\int p\left(y^{T} \mid \theta\right) \pi(\theta) d \theta}
$$

(where I have eliminated the index of the model to ease notation). With the result of the previous subsection, we can evaluate $\pi\left(\theta \mid y^{T}\right.$ ) for a given $\theta$ (up to a proportionality constant), but characterizing the whole posterior is nearly impossible, since we do not even have a close form solution for $p\left(y^{T} \mid \theta\right)$.

This challenge, which for a long time was the main barrier to Bayesian inference, can nowadays easily be addressed by the use of McMc methods. A full exposition of McMc methods would occupy an entire book (as in Robert and Casella 2005). Luckily enough, the basic point is rather straightforward. We want to somehow produce a Markov chain whose ergodic distribution is $\pi\left(\theta \mid y^{T}\right)$. Then, we simulate from the chain and, as the Glivenko-Cantelli theorem does its magic, we approximate $\pi\left(\theta \mid y^{T}\right)$ by the empirical distribution generated by the chain. This twist of McMc methods is pure genius. Usually, we have a theory that implies a Markov chain. For example, our DSGE model implies a Markov process for output and we want to characterize it (this is what chapters 11 to 14 of Stokey et al. 1989, do). In McMc, we proceed backward: we have $\pi\left(\theta \mid y^{T}\right)$ (or at least a procedure to evaluate it) and we come up with a Markov chain that generates it.

This idea would not be very practical unless we had a constructive method to specify the Markov chain. Fortunately, we have such a procedure, although, interestingly enough, only one. This procedure is known as the Metropolis-Hastings algorithm (the Gibbs sampler is a particular case of Metropolis-Hastings). In the MetropolisHastings algorithm, we come up with a new proposed value of the parameter and we evaluate whether it increases the posterior. If it does, we accept it with probability 1. If it does not, we accept it with some probability less than 1 . In such a way, we always go toward the higher regions of the posterior but we also travel, with some 
probability, towards the lower regions. This procedure avoids getting trapped in local maxima. A simple pseudo-code for a plain vanilla Metropolis-Hastings algorithm is as follows:

Step 0, Initialization: Set $i \rightsquigarrow 0$ and an initial $\theta_{i}$. Solve the model for $\theta_{i}$ and build the state space representation. Evaluate $\pi\left(\theta_{i}\right)$ and $p\left(y^{T} \mid \theta_{i}\right)$. Set $i \rightsquigarrow$ $i+1$.

Step 1, Proposal draw: Get a draw $\theta_{i}^{*}$ from a proposal density $q\left(\theta_{i-1}, \theta_{i}^{*}\right)$.

Step 2, Solving the Model: Solve the model for $\theta_{i}^{*}$ and build the new state space representation.

Step 3, Evaluating the proposal: Evaluate $\pi\left(\theta_{i}^{*}\right)$ and $p\left(y^{T} \mid \theta_{i}^{*}\right)$ with (9).

Step 4, Accept/Reject: Draw $\chi_{i} \sim U(0,1)$. If $\chi_{i} \leq \frac{p\left(y^{T} \mid \theta\right) \pi(\theta) q\left(\theta_{i-1}, \theta_{i}^{*}\right)}{p\left(y^{T} \mid \theta\right) \pi(\theta) q\left(\theta_{i}^{*}, \theta_{i-1}\right)}$ set $\theta_{i}=\theta_{i}^{*}$, otherwise $\theta_{i}=\theta_{i-1}$.

Step 5, Iteration: If $i<M$, set $i \rightsquigarrow i+1$ and go to step 1 . Otherwise stop.

This algorithm requires us to specify a proposal density $q(\cdot, \cdot)$. The standard practice (and the easiest) is to choose a random walk proposal, $\theta_{i}^{*}=\theta_{i-1}+\kappa_{i}, \kappa_{i} \sim \mathcal{N}\left(0, \Sigma_{\kappa}\right)$, where $\Sigma_{\kappa}$ is a scaling matrix that the researcher selects to obtain the appropriate acceptance ratio of proposals (Roberts et al. 1997, provide the user with guidelines for the optimal acceptance ratios that maximize the rate of convergence of the empirical distribution toward the ergodic distribution). Of course, we can always follow more sophisticated versions of the algorithm, but for most researchers, the time and effort involved in refinements will not compensate for the improvements in efficiency.

If we are using the particle filter, we need to keep the random numbers of the simulation constant across iterations of the Metropolis-Hastings algorithm. As emphasized by McFadden (1989) and Pakes and Pollard (1989), fixing the random numbers across iterations is required to achieve stochastic equicontinuity. Thanks to it, the pointwise convergence of the likelihood (9) to the exact likelihood we stated above becomes uniform convergence. Although not strictly necessary in a Bayesian context, uniform continuity minimizes the numerical instabilities created by the "chatter" of random numbers across iterations.

Once we have run the algorithm for a sufficient number of iterations (see Mengersen et al. 1999, for a review of convergence tests), we can perform inference: we have an empirical approximation of the posterior of the model and finding means, standard deviations, and other objects of interest is a trivial task. In the interest of space, I omit a discussion of how to select a good initial value $\theta_{0} \cdot{ }^{18}$ The values we would have for a standard calibration exercise are, in general, a good default choice.

The reader who is not familiar with the Metropolis-Hastings algorithm may feel that the previous discussion introduced many concepts. Yes, but none of them is particularly deep once one has thought about them a bit more carefully. Most important,

\footnotetext{
18 The initial states $S_{0}$ for the filter can also be though of as parameters of the model. However, it is usually is easier to sample from the ergodic distribution of states implied by $\theta_{0}$.
} 
once you get the gist of it, McMc methods are surprisingly easy to code, much more, in fact, than even simple optimization algorithms, and they can be easily be recycled for future estimations. This is why I said in Sect. 3 that nowadays doing Bayesian econometrics is easier than doing classical inference.

\section{An application}

The previous pages would look dry and abstract without an application that illustrates how we do things in practice. Hence, I am presenting a simple estimation exercise that I borrow from a recent paper I coauthored with Juan Rubio-Ramírez (FernándezVillaverde and Rubio-Ramirez 2008). Since in that paper we were trying to explore how stable over time were the parameters of DSGE models when we let them vary over time, we took care in estimating a model that could be easily accepted by as many readers as possible as embodying the standard New Keynesian DSGE model. Even if my objectives now are different, the same justification for the model still holds: this will be as standard a model as I know how to write.

Despite any possible vehement claims to the contrary, my choice of application implies an implicit endorsement of the New Keynesian model. If I thought that the model was completely worthless, my behavior would be slightly schizophrenic. And yes, there are good things in the model. It is built around the core of the neoclassical growth model, which is the workhorse of modern macroeconomics and which offers a reasonable account of a set of important stylized facts, both at the long run and business cycle frequencies. Keynes (1936) complained in the General Theory that David Hume had a foot and a half in the classical world. Modern DSGE models fully share this nature. ${ }^{19}$ In addition, the model introduces a number of real and nominal rigidities that generate the higher degree of persistence we see in the data and allow for a non-trivial role of monetary policy, which as we discussed in Sect. 2, perhaps we also find in the data.

However, we need to remember the many shortcomings of the model. We may as well begin with its core, the neoclassical growth model. Growth theorist have accumulated many objections to the basic growth model: it does not have an endogenous mechanism for long-run growth, the existence of a balanced growth path violates some observations in the data, the model does not account for the large cross-country differences in income per capita, and so forth. Our model will suffer from all of those objections.

The second line of criticism regards the nominal rigidities, which are added in an ad hoc way through Calvo pricing. Beyond the lack of microfoundations, Calvo pricing misses many aspects of the microeconomic evidence of pricing behavior by firms documented over the last few years (Álvarez et al. 2005; Bils and Klenow 2004; Bils et al. 2008; Dhyne et al. 2006; Klenow and Kryvtsov 2008; Nakamura and Steinsson

\footnotetext{
19 That is why many argue, with some plausibility, that New Keynesian models are not that Keynesian after all (see Farmer 2007). Given the importance they give to a neoclassical core, the key role of money, and the preference they generate for low and stable inflation, we could just as well call them neomonetarist models. However, after seeing the recent uproar at the University of Chicago regarding the new Milton Friedman Institute for Research in Economics, it is clear that the New Keynesian brand still sells better in many quarters.
} 
2008, among many others). Finally, the model does a terrible job of pricing financial assets, a point I will revisit in Sect. 6.

In the interest of space, I will present only the most basic description of the model without the full background. The interested reader can get many more details at the online appendix http://www.econ.upenn.edu/ jesusfv/benchmark_DSGE.pdf. The basic structure of the model includes a continuum of households that work, consume, and save, a continuum of intermediate good producers that rent capital and labor to manufacture intermediate goods, a final good producer that aggregates the intermediate goods, a labor "packer" that aggregates different types of labor into a homogeneous input, and a government that implements monetary policy by fixing the short-run nominal interest rate through open market operations. Both prices and wages will be subject to rigidities that limit how often they can be changed.

\subsection{The households}

The first type of agents in our model will be the households. We want to have a continuum of them because, in that way, we can generate a whole distribution of wages in the economy, with each household charging its own differentiated wage. At the same time, we do not want to have too much heterogeneity, because this will make computing the model a daunting task. The trick to combine different wages but not a lot of heterogeneity is to assume a separable utility function in consumption and labor and complete markets. Complete markets give us the basic risk-sharing result that, in equilibrium, marginal utilities are equated. If utility is separable in consumption, then perfect risk-sharing implies that all households consume the same amount of the final good and hold the same level of capital, collapsing the distribution of agents along that dimension. Finally, the requirement that we have a balanced growth path implies that we want to consider utility functions of the form:

$$
\mathbb{E}_{0} \sum_{t=0}^{\infty} \beta^{t} d_{t}\left\{\log \left(c_{j t}-h c_{j t-1}\right)+v \log \left(\frac{m o_{j t}}{p_{t}}\right)-\varphi_{t} \psi \frac{l_{j t}^{1+\vartheta}}{1+\vartheta}\right\},
$$

where $j$ is the index of the household, $\mathbb{E}_{0}$ is the conditional expectation operator, $c_{j t}$ is consumption, $m o_{j t} / p_{t}$ are real money balances, $p_{t}$ is the aggregate price level, and $l_{j t}$ is hours worked. In addition, we have the discount factor, $\beta$, a degree of habit persistence, $h$, which will help to induce inertia in the responses of consumption to shocks, and the Frisch labor supply elasticity, $1 / \vartheta$.

The period utility function is shifted by two shocks. First, a shock to intertemporal preferences, $d_{t}$, that works as a demand shock, inducing agents to consume more or less in the current period. Second, a shock to labor supply, to capture the movements in the observed wedge in the first order condition relating consumption and labor (Hall 1997). For simplicity, we postulate that both shocks follow an autoregressive process of order 1 in logs:

$$
\begin{aligned}
\log d_{t} & =\rho_{d} \log d_{t-1}+\sigma_{d} \varepsilon_{d, t} & & \text { where } \varepsilon_{d, t} \sim \mathcal{N}(0,1), \\
\log \varphi_{t} & =\rho_{\varphi} \log \varphi_{t-1}+\sigma_{\varphi} \varepsilon_{\varphi, t} & & \text { where } \varepsilon_{\varphi, t} \sim \mathcal{N}(0,1)
\end{aligned}
$$


The standard deviation of the shocks, $\sigma_{d}$ and $\sigma_{\varphi}$, is constant over time, but we could easily introduce a time component to it (Fernández-Villaverde and Rubio-Ramírez 2007). Time-varying volatility in the shocks helps to understand the changing volatility of U.S. and other Western economies over the last decades that has been named the "Great Moderation" by Stock and Watson (2003).

Households trade on the whole set of Arrow-Debreu securities, contingent on idiosyncratic and aggregate events. My notation $a_{j t+1}$ indicates the amount of those securities that pay one unit of consumption in event $\omega_{j, t+1, t}$ purchased by household $j$ at time $t$ at (real) price $q_{j t+1, t}$. To save on notation, we drop the explicit dependence on the event. Households also hold an amount $b_{j t}$ of government bonds that pay a nominal gross interest rate of $R_{t}$ and invest $x_{t}$. Then, the $j$ th household's budget constraint is:

$$
\begin{aligned}
& c_{j t}+x_{j t}+\frac{m_{j t}}{p_{t}}+\frac{b_{j t+1}}{p_{t}}+\int q_{j t+1, t} a_{j t+1} d \omega_{j, t+1, t} \\
& =w_{j t} l_{j t}+\left(r_{t} u_{j t}-\mu_{t}^{-1} \Phi\left[u_{j t}\right]\right) k_{j t-1}+\frac{m_{j t-1}}{p_{t}}+R_{t-1} \frac{b_{j t}}{p_{t}}+a_{j t}+T_{t}+\digamma_{t},
\end{aligned}
$$

where $w_{j t}$ is the real wage paid per unit of labor, $r_{t}$ the real rental price of capital, $u_{j t}>0$ the utilization rate of capital, $\mu_{t}^{-1} \Phi\left[u_{j t}\right]$ is the physical cost of rate $u_{j t}$ in resource terms (where $\Phi[u]=\Phi_{1}(u-1)+\frac{\Phi_{2}}{2}(u-1)^{2}$ and $\left.\Phi_{1}, \Phi_{2} \geq 0\right), \mu_{t}$ is an investment-specific technological shock that shifts the relative price of capital, $T_{t}$ is a lump-sum transfer from the government, and $\digamma_{t}$ is the household share of the profits of the firms in the economy. This budget constraint is slightly different from a conventional one because households are monopolistic suppliers of their own type of work $j$. Therefore, the household fixes $w_{j t}$ (subject to some rigidities to be specified below) and supplies the amount of labor $l_{j t}$ demanded at that wage. We can think of the household either as an independent businessman who can set its own rate or as a union that negotiates a particular wage rate. This assumption is relatively inconsequential. At the cost of some additional algebra, we could also let firms set wages and households supply the desired labor at such wages.

The law of motion for capital is given by:

$$
k_{j t}=(1-\delta) k_{j t-1}+\mu_{t}\left(1-S\left[\frac{x_{j t}}{x_{j t-1}}\right]\right) x_{j t},
$$

where $\delta$ is the depreciation rate. We have a quadratic adjustment cost function

$$
S\left[\frac{x_{t}}{x_{t-1}}\right]=\frac{\kappa}{2}\left(\frac{x_{t}}{x_{t-1}}-\Lambda_{x}\right)^{2},
$$

where $\kappa \geq 0$ and $\Lambda_{x}$ is the long-run growth of investment. The specification of the adjustment cost function captures the idea that the costs are with respect to moving away from the path of investment growth that we would have in the balanced growth path. In front of investment, we have an investment-specific technological shock $\mu_{t}$ 
that also follows an autoregressive process:

$$
\mu_{t}=\mu_{t-1} \exp \left(\Lambda_{\mu}+z_{\mu, t}\right) \quad \text { where } z_{\mu, t}=\sigma_{\mu} \varepsilon_{\mu, t} \text { and } \varepsilon_{\mu, t} \sim \mathcal{N}(0,1)
$$

The investment-specific technological shock accounts for the fall in the relative price of capital observed in the U.S. economy since the Second World War and it plays a crucial role in accounting for long-run growth and in generating business cycle fluctuations (see the rather compelling evidence in Greenwood et al. 1997, 2000). The process for investment-specific technological change generates the first unit root in the model and it will be one source of growth in the economy.

The Lagrangian function that summarizes the problem of the household is given by:

$$
\mathbb{E}_{0} \sum_{t=0}^{\infty} \beta^{t}\left[-\lambda_{t}\left\{\begin{array}{c}
d_{t}\left\{\log \left(c_{j t}-h c_{j t-1}\right)+v \log \left(\frac{m_{j t}}{p_{t}}\right)-\varphi_{t} \psi \frac{l_{j t}^{1+\vartheta}}{1+\vartheta}\right\} \\
c_{j t}+x_{j t}+\frac{m_{j t}}{p_{t}}+\frac{b_{j t}}{p_{t}}+\int q_{j t+1, t} a_{j t+1} d \omega_{j, t+1, t} \\
-w_{j t} l_{j t}-\left(r_{t} u_{j t}-\mu_{t}^{-1} \Phi\left[u_{j t}\right]\right) k_{j t-1}-\frac{m_{j t-1}}{p_{t}}-R_{t-1} \frac{b_{j t-1}}{p_{t}}-a_{j t}-T_{t}-\digamma_{t}
\end{array}\right\}\right],
$$

where the household chooses $c_{j t}, b_{j t}, u_{j t}, k_{j t}, x_{j t}, w_{j t}, l_{j t}$ and $a_{j t+1}$ (maximization with respect to money holdings comes from the budget constraint), $\lambda_{t}$ is the Lagrangian multiplier associated with the budget constraint, and $Q_{t}$ the Lagrangian multiplier associated with the law of motion of capital. Since I argued before that with complete markets and separable utility, marginal utilities will be equated in all states of nature and all periods, I do not need to index the multipliers by $j$.

The first order conditions with respect to $c_{j t}, b_{j t}, u_{j t}, k_{j t}$, and $x_{j t}$ are:

$$
\begin{aligned}
& d_{t}\left(c_{j t}-h c_{j t-1}\right)^{-1}-h \beta \mathbb{E}_{t} d_{t+1}\left(c_{j t+1}-h c_{j t}\right)^{-1}=\lambda_{t}, \\
& \lambda_{t}=\beta \mathbb{E}_{t}\left\{\lambda_{t+1} \frac{R_{t}}{\Pi_{t+1}}\right\}, \\
& r_{t}=\mu_{t}^{-1} \Phi^{\prime}\left[u_{j t}\right], \\
& Q_{t}=\beta \mathbb{E}_{t}\left\{(1-\delta) Q_{t+1}+\lambda_{t+1}\left(r_{t+1} u_{j t+1}-\mu_{t+1}^{-1} \Phi\left[u_{j t+1}\right]\right)\right\}, \\
& \quad-\lambda_{t}+Q_{t} \mu_{t}\left(1-S\left[\frac{x_{j t}}{x_{j t-1}}\right]-S^{\prime}\left[\frac{x_{j t}}{x_{j t-1}}\right] \frac{x_{j t}}{x_{j t-1}}\right) \\
& \quad+\beta \mathbb{E}_{t} Q_{t+1} \mu_{t+1} S^{\prime}\left[\frac{x_{j t+1}}{x_{j t}}\right]\left(\frac{x_{j t+1}}{x_{j t}}\right)^{2}=0 .
\end{aligned}
$$

I do not include the first order conditions with respect to Arrow-Debreu securities, since we do not need them to solve for the equilibrium of the economy. Nevertheless, those first order conditions will be useful below to price the securities. In particular, 
from the second equation, we can see that

$$
\frac{\lambda_{j t+1}}{\lambda_{j t}}=\frac{d_{t}\left(c_{j t+1}-h c_{j t}\right)^{-1}-h \beta \mathbb{E}_{t+1} d_{t+2}\left(c_{j t+2}-h c_{j t+1}\right)^{-1}}{d_{t}\left(c_{j t}-h c_{j t-1}\right)^{-1}-h \beta \mathbb{E}_{t} d_{t+1}\left(c_{j t+1}-h c_{j t}\right)^{-1}}
$$

is the pricing kernel of the economy.

If we define the (marginal) Tobin's $Q$ as $q_{t}=\frac{Q_{t}}{\lambda_{t}}$ (the value of installed capital in terms of its replacement cost), we find:

$$
\begin{aligned}
q_{t}= & \beta \mathbb{E}_{t}\left\{\frac{\lambda_{t+1}}{\lambda_{t}}\left((1-\delta) q_{t+1}+r_{t+1} u_{j t+1}-\mu_{t+1}^{-1} \Phi\left[u_{j t+1}\right]\right)\right\}, \\
1= & q_{t} \mu_{t}\left(1-S\left[\frac{x_{j t}}{x_{j t-1}}\right]-S^{\prime}\left[\frac{x_{j t}}{x_{j t-1}}\right] \frac{x_{j t}}{x_{j t-1}}\right) \\
& +\beta \mathbb{E}_{t} q_{t+1} \mu_{t+1} \frac{\lambda_{j t+1}}{\lambda_{j t}} S^{\prime}\left[\frac{x_{j t+1}}{x_{j t}}\right]\left(\frac{x_{j t+1}}{x_{j t}}\right)^{2} .
\end{aligned}
$$

The first equation tells us that the relative price of capital is equal to the (expected) return we will get from it in the next period

$$
\underbrace{(1-\delta) q_{t+1}}_{\text {Sale Value }}+\underbrace{r_{t+1} u_{j t+1}}_{\text {Rental Payment }}-\underbrace{\mu_{t+1}^{-1} \Phi\left[u_{j t+1}\right]}_{\text {Compensation for Utilization Rate }}
$$

times the pricing kernel. The second equation determines that if $S[\cdot]=0$ (i.e., there are no adjustment costs), we get:

$$
q_{t}=\frac{1}{\mu_{t}}
$$

i.e., the marginal Tobin's $Q$ is equal to the replacement cost of capital (the relative price of capital), which falls over time as $\mu_{t}$ increases. Furthermore, if $\mu_{t}=1$ (as we have in the basic real business cycle model), the relative price of capital is trivially equated to 1 .

The necessary conditions with respect to labor and wages are more involved. There is a labor "packer" that aggregates the differentiated labor supplied by each household into a homogeneous labor unit that intermediate good producers hire in a competitive market. The aggregation is done through the following production function:

$$
l_{t}^{d}=\left(\int_{0}^{1} l_{j t}^{\frac{\eta-1}{\eta}} d j\right)^{\frac{\eta}{\eta-1}}
$$

where $0 \leq \eta<\infty$ is the elasticity of substitution among different types of labor and $l_{t}^{d}$ is the aggregate labor demand. 
The labor "packer" maximizes profits subject to the production function (10), taking as given all differentiated labor wages $w_{j t}$ and the wage $w_{t}$ for $l_{t}^{d}$. Consequently, its maximization problem is:

$$
\max _{l_{j t}} w_{t} l_{t}^{d}-\int_{0}^{1} w_{j t} l_{j t} d j .
$$

After some algebra, we get the input demand functions associated with this problem:

$$
l_{j t}=\left(\frac{w_{j t}}{w_{t}}\right)^{-\eta} l_{t}^{d} \forall j,
$$

which shows that the elasticity of substitution also controls the elasticity of demand for $j$ th type of labor with respect to wages. Then, by using the zero profit condition for the labor "packer":

$$
w_{t}=\left(\int_{0}^{1} w_{j t}^{1-\eta} d j\right)^{\frac{1}{1-\eta}}
$$

Now we can specify the wage-setting mechanism. There are several mechanisms for introducing wage rigidities but one that is particularly clever and simple is a timedependent rule called Calvo pricing. In each period, a fraction $1-\theta_{w}$ of households can reoptimize their wages and set a nominal value $p_{t} w_{j t}$. All other households can only partially index their wages by past inflation with an indexation parameter $\chi_{w} \in[0,1]$. Therefore, the real wage of a household that has not been able to reoptimize it for $\tau$ periods is:

$$
\prod_{s=1}^{\tau} \frac{\Pi_{t+s-1}^{\chi_{w}}}{\Pi_{t+s}} w_{j t} .
$$

The probability $1-\theta_{w}$ is the reduced-form representation of a more microfounded origin of wage rigidities (quadratic adjustment costs as in the original Calvo paper, 1983, contract costs, Caplin and Leahy 1991, 1997, or information limitations, Mankiw and Reis 2002, or Sims 2002), which we do not include in the model to keep the number of equations within reasonable bounds. In Sect. 6, I will discuss the problems of Calvo pricing in detail. Suffice it to say here that, despite many potential problems, Calvo pricing is so simple that it still constitutes the natural benchmark for price and wage rigidities. This is due to the memoryless structure of the mechanism: we do not need to keep track of when wages reoptimized the last time, since $\theta_{w}$ is time independent.

Relying on the separability of the utility function and the presence of complete markets, the only part of the Lagrangian that gets affected by the wage and labor supply decisions of the household is: 


$$
\max _{w_{j t}} \mathbb{E}_{t} \sum_{\tau=0}^{\infty}\left(\beta \theta_{w}\right)^{\tau}\left\{-d_{t} \varphi_{t} \psi \frac{l_{j t+\tau}^{1+\vartheta}}{1+\vartheta}+\lambda_{t+\tau} \prod_{s=1}^{\tau} \frac{\Pi_{t+s-1}^{\chi_{w}}}{\Pi_{t+s}} w_{j t} l_{j t+\tau}\right\}
$$

subject to

$$
l_{j t+\tau}=\left(\prod_{s=1}^{\tau} \frac{\Pi_{t+s-1}^{\chi_{w}}}{\Pi_{t+s}} \frac{w_{j t}}{w_{t+\tau}}\right)^{-\eta} l_{t+\tau}^{d} \forall j
$$

Note how we have modified the discount factor to include the probability $\theta_{w}$ that the household has to keep the wage for one more period. Once the household can reoptimize, the continuation of the decision problem is independent from our choice of wage today, and hence, we do not need to include it in the section of the Lagrangian in Eq. (12). We also assume that

$$
\left(\beta \theta_{w}\right)^{\tau} \lambda_{t+\tau} \prod_{s=1}^{\tau} \frac{\Pi_{t+s-1}^{\chi_{w}}}{\Pi_{t+s}}
$$

goes to zero for the previous sum to be well defined.

Also, because of complete markets, all of the households reoptimazing wages in the current period will pick the same wage and we can drop the $j$ th from $w_{j t}$. The first order condition of this problem is then:

$$
\begin{aligned}
& \frac{\eta-1}{\eta} w_{t}^{*} \mathbb{E}_{t} \sum_{\tau=0}^{\infty}\left(\beta \theta_{w}\right)^{\tau} \lambda_{t+\tau}\left(\prod_{s=1}^{\tau} \frac{\Pi_{t+s-1}^{\chi_{w}}}{\Pi_{t+s}}\right)^{1-\eta}\left(\frac{w_{t}^{*}}{w_{t+\tau}}\right)^{-\eta} l_{t+\tau}^{d} \\
& =\mathbb{E}_{t} \sum_{\tau=0}^{\infty}\left(\beta \theta_{w}\right)^{\tau}\left(d_{t+\tau} \varphi_{t+\tau} \psi\left(\prod_{s=1}^{\tau} \frac{\Pi_{t+s-1}^{\chi_{w}}}{\Pi_{t+s}} \frac{w_{t}^{*}}{w_{t+\tau}}\right)^{-\eta(1+\vartheta)}\left(l_{t+\tau}^{d}\right)^{1+\vartheta}\right),
\end{aligned}
$$

where $w_{t}^{*}$ is the new optimal wage. This expression involves infinite sums that are difficult to handle computationally. It is much simpler to write the first order conditions as $f_{t}^{1}=f_{t}^{2}$ where we have the recursive functions:

$$
f_{t}^{1}=\frac{\eta-1}{\eta}\left(w_{t}^{*}\right)^{1-\eta} \lambda_{t} w_{t}^{\eta} l_{t}^{d}+\beta \theta_{w} \mathbb{E}_{t}\left(\frac{\Pi_{t}^{\chi_{w}}}{\Pi_{t+1}}\right)^{1-\eta}\left(\frac{w_{t+1}^{*}}{w_{t}^{*}}\right)^{\eta-1} f_{t+1}^{1}
$$

and:

$$
f_{t}^{2}=\psi d_{t} \varphi_{t}\left(\frac{w_{t}}{w_{t}^{*}}\right)^{\eta(1+\vartheta)}\left(l_{t}^{d}\right)^{1+\vartheta}+\beta \theta_{w} \mathbb{E}_{t}\left(\frac{\Pi_{t}^{\chi_{w}}}{\Pi_{t+1}}\right)^{-\eta(1+\vartheta)}\left(\frac{w_{t+1}^{*}}{w_{t}^{*}}\right)^{\eta(1+\vartheta)} f_{t+1}^{2}
$$


Now, if we put the previous equations together and drop the $j$ 's indexes (that are redundant), we have the first order conditions

$$
\begin{gathered}
d_{t}\left(c_{t}-h c_{t-1}\right)^{-1}-h \beta \mathbb{E}_{t} d_{t+1}\left(c_{t}-h c_{t}\right)^{-1}=\lambda_{t}, \\
\lambda_{t}=\beta \mathbb{E}_{t}\left\{\lambda_{t+1} \frac{R_{t}}{\Pi_{t+1}}\right\}, \\
r_{t}=\mu_{t}^{-1} \Phi^{\prime}\left[u_{t}\right], \\
q_{t}=\beta \mathbb{E}_{t}\left\{\frac{\lambda_{t+1}}{\lambda_{t}}\left[(1-\delta) q_{t+1}+\left(r_{t+1} u_{t+1}-\mu_{t+1}^{-1} \Phi\left[u_{t+1}\right]\right)\right]\right\}, \\
1=q_{t} \mu_{t}\left(1-S\left[\frac{x_{t}}{x_{t-1}}\right]-S^{\prime}\left[\frac{x_{t}}{x_{t-1}}\right] \frac{x_{t}}{x_{t-1}}\right)+\beta \mathbb{E}_{t} q_{t} \mu_{t+1} \frac{\lambda_{t+1}}{\lambda_{t}} S^{\prime}\left[\frac{x_{t+1}}{x_{t}}\right]\left(\frac{x_{t+1}}{x_{t}}\right)^{2} .
\end{gathered}
$$

the budget constraint:

$$
\begin{aligned}
& c_{j t}+x_{j t}+\frac{m_{j t}}{p_{t}}+\frac{b_{j t+1}}{p_{t}}+\int q_{j t+1, t} a_{j t+1} d \omega_{j, t+1, t} \\
& =w_{j t} l_{j t}+\left(r_{t} u_{j t}-\mu_{t}^{-1} \Phi\left[u_{j t}\right]\right) k_{j t-1}+\frac{m_{j t-1}}{p_{t}}+R_{t-1} \frac{b_{j t}}{p_{t}}+a_{j t}+T_{t}+\digamma_{t}
\end{aligned}
$$

and the laws of motion for $f_{t}$ :

$$
f_{t}=\frac{\eta-1}{\eta}\left(w_{t}^{*}\right)^{1-\eta} \lambda_{t} w_{t}^{\eta} l_{t}^{d}+\beta \theta_{w} \mathbb{E}_{t}\left(\frac{\Pi_{t}^{\chi_{w}}}{\Pi_{t+1}}\right)^{1-\eta}\left(\frac{w_{t+1}^{*}}{w_{t}^{*}}\right)^{\eta-1} f_{t+1}
$$

and:

$f_{t}=\psi d_{t} \varphi_{t}\left(\Pi_{t}^{* w}\right)^{-\eta(1+\vartheta)}\left(l_{t}^{d}\right)^{1+\vartheta}+\beta \theta_{w} \mathbb{E}_{t}\left(\frac{\Pi_{t}^{\chi_{w}}}{\Pi_{t+1}}\right)^{-\eta(1+\vartheta)}\left(\frac{w_{t+1}^{*}}{w_{t}^{*}}\right)^{\eta(1+\vartheta)} f_{t+1}$, where $\Pi_{t}^{* w}=w_{t}^{*} / w_{t}$.

The real wage evolves as a geometric average of the past real wage and the new optimal wage:

$$
w_{t}^{1-\eta}=\theta_{w}\left(\frac{\Pi_{t-1}^{\chi_{w}}}{\Pi_{t}}\right)^{1-\eta} w_{t-1}^{1-\eta}+\left(1-\theta_{w}\right) w_{t}^{* 1-\eta}
$$

\subsection{The final good producer}

There is one final good producer that aggregates intermediate goods $y_{i t}$ with the production function:

$$
y_{t}^{d}=\left(\int_{0}^{1} y_{i t}^{\frac{\varepsilon-1}{\varepsilon}} d i\right)^{\frac{\varepsilon}{\varepsilon-1}},
$$


where $\varepsilon$ is the elasticity of substitution. Similarly to the labor "packer," the final good producer is perfectly competitive and maximizes profits subject to the production function (13), taking as given all intermediate goods prices $p_{t i}$ and the final good price $p_{t}$. Thus, the input demand functions associated with this problem are:

$$
y_{i t}=\left(\frac{p_{i t}}{p_{t}}\right)^{-\varepsilon} y_{t}^{d} \quad \forall i
$$

where $y_{t}^{d}$ is aggregate demand and the price level is:

$$
p_{t}=\left(\int_{0}^{1} p_{i t}^{1-\varepsilon} d i\right)^{\frac{1}{1-\varepsilon}}
$$

\subsection{Intermediate good producers}

As mentioned above, there is a continuum of intermediate goods producers, each of which has access to a production function $y_{i t}=A_{t} k_{i t-1}^{\alpha}\left(l_{i t}^{d}\right)^{1-\alpha}-\phi z_{t}$ where $k_{i t-1}$ is the capital rented by the firm, $l_{i t}^{d}$ is the amount of the labor input rented from the labor "packer," and where $A_{t}$, a neutral technology level, evolves as:

$$
A_{t}=A_{t-1} \exp \left(\Lambda_{A}+z_{A, t}\right) \quad \text { where } z_{A, t}=\sigma_{A} \varepsilon_{A, t} \text { and } \varepsilon_{A, t} \sim \mathcal{N}(0,1) \text {. }
$$

This process incorporates a second unit root in the model. The fixed cost of production $\phi$ is indexed by the variable $z_{t}=A_{t}^{\frac{1}{1-\alpha}} \mu_{t}^{\frac{\alpha}{1-\alpha}}$ to make it grow with the economy (think, for example, of the fixed cost of paying some fees for keeping the factory open: it is natural to think that the fees will increase with income). Otherwise, the fixed cost would become asymptotically irrelevant. In a balanced growth path, $z_{t}$ is precisely the growth factor in the economy that we want to scale for. The role of the fixed cost is to roughly eliminate profits in equilibrium and to allow us to dispense with the entry and exit of intermediate good producers.

Since $z_{t}=A_{t}^{\frac{1}{1-\alpha}} \mu_{t}^{\frac{\alpha}{1-\alpha}}$, we can combine the processes for $A_{t}$ and $\mu_{t}$ to get:

$$
z_{t}=z_{t-1} \exp \left(\Lambda_{z}+z_{z, t}\right) \quad \text { where } z_{z, t}=\frac{z_{A, t}+\alpha z_{\mu, t}}{1-\alpha} \text { and } \Lambda_{z}=\frac{\Lambda_{A}+\alpha \Lambda_{\mu}}{1-\alpha}
$$

Many of the variables in the economy, like $c_{t}$, will be cointegrated in equilibrium with $z_{t}$. This cointegration captures the evidence of constant main ratios of the economy in a stochastic trend environment with the advantage that, with respect to the empirical literature, the cointegration vector is microfounded and implied by the optimization decision of the agents in the model and not exogenously postulated by the econometrician (for the origin of this idea, see King et al. 1991). 
The problem of intermediate goods producers can be chopped into two parts. First, given input prices $w_{t}$ and $r_{t}$, they rent $l_{i t}^{d}$ and $k_{i t-1}$ to minimize real cost:

$$
\min _{l_{i t}^{d}, k_{i t-1}} w_{t} l_{i t}^{d}+r_{t} k_{i t-1}
$$

subject to their supply curve:

$$
y_{i t}= \begin{cases}A_{t} k_{i t-1}^{\alpha}\left(l_{i t}^{d}\right)^{1-\alpha}-\phi z_{t}, & \text { if } A_{t} k_{i t-1}^{\alpha}\left(l_{i t}^{d}\right)^{1-\alpha} \geq \phi z_{t}, \\ 0, & \text { otherwise. }\end{cases}
$$

The solution of this problem implies that all intermediate good firms equate their capital-labor ratio to the ratio of input prices times a constant:

$$
\frac{k_{i t-1}}{l_{i t}^{d}}=\frac{\alpha}{1-\alpha} \frac{w_{t}}{r_{t}}
$$

and that the marginal cost $m c_{t}$ is

$$
m c_{t}=\left(\frac{1}{1-\alpha}\right)^{1-\alpha}\left(\frac{1}{\alpha}\right)^{\alpha} \frac{w_{t}^{1-\alpha} r_{t}^{\alpha}}{A_{t}}
$$

A useful observation is that neither of these expressions depends on $i$ since $A_{t}$ and input prices are common for all firms.

The second part of the problem is to set a price for the intermediate good. In a similar vein to the household, the intermediate good producer is subject to Calvo pricing, where now the probability of reoptimizing prices is $1-\theta_{p}$ and the indexation parameter is $\chi \in[0,1]$.

Therefore, the problem of the firms is:

$$
\max _{p_{i t}} \mathbb{E}_{t} \sum_{\tau=0}^{\infty}\left(\beta \theta_{p}\right)^{\tau} \frac{\lambda_{t+\tau}}{\lambda_{t}}\left\{\left(\prod_{s=1}^{\tau} \Pi_{t+s-1}^{\chi} \frac{p_{i t}}{p_{t+\tau}}-m c_{t+\tau}\right) y_{i t+\tau}\right\}
$$

subject to

$$
y_{i t+\tau}=\left(\prod_{s=1}^{\tau} \Pi_{t+s-1}^{\chi} \frac{p_{i t}}{p_{t+\tau}}\right)^{-\varepsilon} y_{t+\tau}^{d}
$$

where future profits are valued using the pricing kernel $\lambda_{t+\tau} / \lambda_{t}$. 
The first order condition of this problem, after some algebra and noticing that $p_{i t}^{*}=p_{t}^{*}$,

$$
\begin{gathered}
\mathbb{E}_{t} \sum_{\tau=0}^{\infty}\left(\beta \theta_{p}\right)^{\tau} \lambda_{t+\tau}\left\{\left((1-\varepsilon)\left(\prod_{s=1}^{\tau} \frac{\Pi_{t+s-1}^{\chi}}{\Pi_{t+s}}\right)^{1-\varepsilon} \frac{p_{t}^{*}}{p_{t}}\right.\right. \\
\left.\left.\quad+\varepsilon\left(\prod_{s=1}^{\tau} \frac{\Pi_{t+s-1}^{\chi}}{\Pi_{t+s}}\right)^{-\varepsilon} m c_{t+\tau}\right) y_{t+\tau}^{d}\right\}=0 .
\end{gathered}
$$

This expression tells us that the price is equal to a weighted sum of future expected mark-ups. We can express this condition recursively as:

$$
\begin{aligned}
\varepsilon g_{t}^{1} & =(\varepsilon-1) g_{t}^{2}, \\
g_{t}^{1} & =\lambda_{t} m c_{t} y_{t}^{d}+\beta \theta_{p} \mathbb{E}_{t}\left(\frac{\Pi_{t}^{\chi}}{\Pi_{t+1}}\right)^{-\varepsilon} g_{t+1}^{1}, \\
g_{t}^{2} & =\lambda_{t} \Pi_{t}^{*} y_{t}^{d}+\beta \theta_{p} \mathbb{E}_{t}\left(\frac{\Pi_{t}^{\chi}}{\Pi_{t+1}}\right)^{1-\varepsilon}\left(\frac{\Pi_{t}^{*}}{\Pi_{t+1}^{*}}\right) g_{t+1}^{2},
\end{aligned}
$$

where:

$$
\Pi_{t}^{*}=\frac{p_{t}^{*}}{p_{t}}
$$

Given Calvo's pricing, the price index evolves as:

$$
1=\theta_{p}\left(\frac{\Pi_{t-1}^{\chi}}{\Pi_{t}}\right)^{1-\varepsilon}+\left(1-\theta_{p}\right) \Pi_{t}^{* 1-\varepsilon}
$$

\subsection{The government problem}

The last agent in the model is the government. To simplify things I forget about fiscal policy and I assume that the government follows a simple Taylor rule:

$$
\frac{R_{t}}{R}=\left(\frac{R_{t-1}}{R}\right)^{\gamma_{R}}\left(\left(\frac{\Pi_{t}}{\Pi}\right)^{\gamma_{\Pi}}\left(\frac{\frac{y_{t}^{d}}{y_{t-1}^{d}}}{\Lambda_{z}}\right)^{\gamma_{y}}\right)^{1-\gamma_{R}} \exp \left(m_{t}\right)
$$

that sets the short-term nominal interest rates as a function of past interest rates, inflation and the "growth gap": the ratio between the growth of aggregate demand, $\frac{y_{t}^{d}}{y_{t-1}^{d}}$, and the average growth of the economy, $\Lambda_{z}$. Introducing this growth gap avoids the need to specify a measure of the output gap (always somehow arbitrary) and, more 
important, fits the evidence better (Orphanides 2002). The term $m_{t}$ is a random shock to monetary policy such that $m_{t}=\sigma_{m} \varepsilon_{m t}$, where $\varepsilon_{m t} \sim \mathcal{N}(0,1)$.

The other elements in the Taylor rule are the target level of inflation, $\Pi$, and the steady state nominal gross return of capital, $R$. Since we are dealing with a general equilibrium model, the government can pick either $\Pi$ or $R$ but not both ( $R$ is equal to $\Pi$ times the steady state real interest rate).

The nominal interest rate can be implemented either through open market operations (as has been the norm for the last several decades) or through paying interest on bank reserves (as the Fed has recently begun to do in the United States). In both cases, monetary policy generates either a surplus (or a deficit) that is eliminated through lump-sum transfers $T_{t}$ to households.

\subsection{Aggregation, equilibrium, and solution}

Now, we can add all of the previous expressions to find aggregate variables and define an equilibrium. First, we have aggregate demand, $y_{t}^{d}=c_{t}+x_{t}+\mu_{t}^{-1} \Phi\left[u_{t}\right] k_{t-1}$. Second, by noticing that all the intermediate good firms will have the same capital-labor ratio, we can find aggregate supply:

$$
y_{t}=\frac{A_{t}\left(u_{t} k_{t-1}\right)^{\alpha}\left(l_{t}^{d}\right)^{1-\alpha}-\phi z_{t}}{v_{t}^{p}}
$$

where

$$
v_{t}^{p}=\int_{0}^{1}\left(\frac{p_{i t}}{p_{t}}\right)^{-\varepsilon} d i
$$

is an inefficiency factor created by price dispersion, and

$$
l_{t}^{d}=\frac{l_{t}}{v_{t}^{w}}
$$

is labor packed where

$$
v_{t}^{w}=\int_{0}^{1}\left(\frac{w_{j t}}{w_{t}}\right)^{-\eta} d j
$$

is an inefficiency factor created by wage dispersion. Furthermore, by Calvo's pricing

$$
v_{t}^{p}=\theta_{p}\left(\frac{\Pi_{t-1}^{\chi}}{\Pi_{t}}\right)^{-\varepsilon} v_{t-1}^{p}+\left(1-\theta_{p}\right) \Pi_{t}^{*-\varepsilon}
$$


and

$$
v_{t}^{w}=\theta_{w}\left(\frac{w_{t-1}}{w_{t}} \frac{\Pi_{t-1}^{\chi_{w}}}{\Pi_{t}}\right)^{-\eta} v_{t-1}^{w}+\left(1-\theta_{w}\right)\left(\Pi_{t}^{w *}\right)^{-\eta}
$$

A definition of equilibrium in this economy is standard and it is characterized by first order conditions of the household, the first order conditions of the firms, the recursive definitions of $g_{t}^{1}$ and $g_{t}^{2}$, the Taylor rule of the government, and market clearing.

Since the model has two unit roots, one in the investment-specific technological change and one in the neutral technological change, we need to rescale all the variables to avoid solving the model with non-stationary variables (a solution that is feasible, but most cumbersome). The scaling will be given by the variable $z_{t}$ in such a way that, for any arbitrary variable $x_{t}$, we will have $\widetilde{x}_{t}=x_{t} / z_{t}$. Partial exceptions are the variables, $\widetilde{r}_{t}=r_{t} \mu_{t}, \widetilde{q}_{t}=q_{t} \mu_{t}$, and $\widetilde{k}_{t}=\frac{k_{t}}{z_{t} \mu_{t}}$. Once the model has been rescaled, we can find the steady state and solve the model by loglinearizating around the steady state.

Loglinearization is both a fast and efficient method for solving large-scale DSGE models. I have documented elsewhere (Aruoba et al. 2006), that it is a nice compromise between speed and accuracy in many applications of interest. Furthermore, it can easily be extended to include higher order terms (Judd 1998). Once I have solved the model, I use the Kalman filter to evaluate the likelihood of the model, given some parameter values. The whole process takes less than 1 second per evaluation of the likelihood.

\subsection{Observables}

I estimate the DSGE model using five time series for the U.S. economy: (1) the relative price of investment with respect to the price of consumption, (2) real output per capita growth, (3) real wages per capita, (4) the consumer price index, and (5) the federal funds rate (the interest rate at which banks lend balances at the Federal Reserve System to each other, usually overnight). This series captures the main aspects of the dynamics of the data and model much of the information that a policy maker is interested in. The sample is 1959.Q1-2007.Q1.

To find the real output per capita series, I first define nominal output as nominal consumption plus nominal gross investment. Nominal consumption is the sum of personal consumption expenditures on non-durable goods and services while nominal gross investment is the sum of personal consumption expenditures on durable goods, private residential investment, and non-residential fixed investment. Per capita nominal output is equal to the ratio between our nominal output series and the civilian non-institutional population between 16 and 65. I transform nominal quantities into real ones using the investment deflator computed by Fisher (2006), a series that unfortunately ends early in 2000:Q4. Following Fisher's methodology, I have extended the series to 2007:Q1. Real wages are defined as compensation per hour in the non-farm business sector divided by the CPI deflator. 
Note that I directly map all my observed variables into objects from the model without a previous filtering (first differences is, strictly speaking, a filter, but it comes directly from the unit roots processes that I postulate for technology). Often, the literature passes the data through some filter such as Hodrick-Prescott before introducing them in the measurement equation. Canova (2008) and Canova and Ferroni (2009) discuss this practice and evaluate different filtering alternatives. Suffice it to say here that I have always been skeptical of filtering procedures not implied by the theory and critical of Hodrick-Prescott filtering in this context because it does not impose a common (or related) trend among variables that should have a common trend (after all, this is the key point of cointegration analysis). However, given the lessons in Hansen and Sargent (1993) regarding the use of seasonally adjusted data, I remain relatively open to new research exploring this topic. ${ }^{20}$

\subsection{Priors}

My next step is to specify priors. In this task, there are two possibilities. Some researchers prefer to select loose priors and let the likelihood dominate the posterior as much as feasible. While this option prioritizes the role of data over the beliefs of the researcher, it also complicates identification and may lead to odd estimates when the model is seriously misspecified along some dimension. Other researchers favor tighter priors that sharpen our inference and guide the posterior to plausible regions. My personal view is that eliciting priors is a problem that one needs to face from the perspective of the particular application one has in mind for the model. For instance, if the model is going to be used for policy analysis, tighter priors are probably a better option since they facilitate the estimation of larger models and ensure that the model behaves "reasonably," an important consideration when the results need to be communicated to policy-makers. If, instead, the model is going to be used for pure research, looser priors are probably a better option. In any case, an explicit prior robustness analysis that determines how much our prior is influencing the posterior is a relatively easy task to implement (see Geweke 1998, for a simple importance sampling algorithm for prior sensitivity analysis that is trivially easy to implement). Unfortunately, editors and referees are rarely keen on seeing this analysis in the final version of the paper.

Also, one can specify priors directly on the parameter values, which is more transparent but sometimes unnatural, or indirectly though the implications of these priors for steady state relationships and second moments of the endogenous variables about which we can have more concrete beliefs. Del Negro and Schorfheide (2008) is a nice example of this route and also a good place to learn about the effect of priors on our inference.

\footnotetext{
20 Seasonal adjustment is another source of possible difficulties, not only for the estimation of DSGE models but for empirical macro in general. Statistical agencies employ purely empirical methods to separate seasonal from lower frequency components in the data and this adjustment may suffer from problems of its own (for instance, being dependent on the cyclical position of the economy) that can contaminate our estimates. Similar concerns are raised by the different vintages of data releases.
} 
Table 1 Priors

\begin{tabular}{llllll}
\hline $100\left(\beta^{-1}-1\right)$ & $h$ & $\psi$ & $\theta_{p}$ & $\chi$ & $\theta_{w}$ \\
$G a(0.25,0.1)$ & $B e(0.7,0.1)$ & $N(9,3)$ & $B e(0.5,0.1)$ & $B e(0.5,0.15)$ & $B e(0.5,0.1)$ \\
$\chi_{w}$ & $\gamma_{R}$ & $\gamma_{y}$ & $\gamma_{\pi}$ & $100(\Pi-1)$ & $\vartheta$ \\
$B e(0.5,0.1)$ & $B e(0.75,0.1)$ & $N(0.12,0.05)$ & $N(1.5,0.125)$ & $G a(0.95,0.1)$ & $N(1,0.25)$ \\
$\kappa$ & $\alpha$ & $\rho_{d}$ & $\rho_{\varphi}$ & $\exp \left(\sigma_{A}\right)$ & $\exp \left(\sigma_{d}\right)$ \\
$N(4,1.5)$ & $N(0.3,0.025)$ & $B e(0.5,0.2)$ & $B e(0.5,0.2)$ & $I G(0.1,2)$ & $I G(0.1,2)$ \\
$\exp \left(\sigma_{\varphi}\right)$ & $\exp \left(\sigma_{\mu}\right)$ & $\exp \left(\sigma_{e}\right)$ & $100 \Lambda_{\mu}$ & $100 \Lambda_{A}$ & \\
$I G(0.1,2)$ & $I G(0.1,2)$ & $I G(0.1,2)$ & $N(0.34,0.1)$ & $N(0.178,0.075)$ & \\
\hline
\end{tabular}

Table 2 Fixed parameters

\begin{tabular}{lllll}
\hline$\delta$ & $\varepsilon$ & $\eta$ & $\phi$ & $\Phi_{2}$ \\
\hline 0.025 & 10 & 10 & 0 & 0.001 \\
\hline
\end{tabular}

To facilitate the task of the reader who wants to continue exploring the estimation of DSGE models without further ado, I would follow the choices of Smets and Wouters (2007) with a few trivial changes. Instead of a long (and, most likely, boring) discussion of each prior, I just point out that I am selecting mainstream priors that are centered around the median value of estimates of micro and macro data. Also, I fix some parameters that are very difficult to identify in the data. The priors are given in Table 1 and the fixed parameters are given in Table 2.

Perhaps the only two fixed parameters that are interesting to discuss are $\varepsilon$ and $\eta$, both with a value of 10 . These values imply an average mark-up of around $10 \%$, in line with many estimates.

\subsection{Empirical results}

I generate 75,000 draws from the posterior using a random walk Metropolis-Hastings. While 75,000 draws is a comparatively low number, there was a substantial and long search for good initial parameter values, which means that the estimates were stable and passed all the usual tests of convergence. The posterior medians and the 5 and 95 percentile values of the 23 estimated parameters of the model are reported in Table 3. Figure 1 plots the histograms of each parameter (one can think of the likelihood as the combination of all those histograms in a highly dimensional object). ${ }^{21}$ A histogram as this one is always a good way to summarize the posterior (humans grasping pictures much more easily than numbers) and, also, a good procedure to assess the strength of the identification of different parameters. Fortunately, in our case, it seems that identification is strong enough, not a surprise given that we use the relatively tight priors of Smets and Wouters (2007).

\footnotetext{
21 These results are also reported in Fernández-Villaverde et al. (2008).
} 
Table 3 Median estimated parameters (5 and 95 per. in parentheses)

\begin{tabular}{llllll}
\hline$\beta$ & $h$ & $\psi$ & $\vartheta$ & $\kappa$ & $\alpha$ \\
0.998 & 0.97 & 8.92 & 1.17 & 9.51 & 0.21 \\
{$[0.997,0.999]$} & {$[0.95,0.98]$} & {$[4.09,13.84]$} & {$[0.74,1.61]$} & {$[7.47,11.39]$} & {$[0.17,0.26]$} \\
$\theta_{p}$ & $\chi$ & $\theta_{w}$ & $\chi_{w}$ & $\gamma_{R}$ & $\gamma_{y}$ \\
0.82 & 0.63 & 0.68 & 0.62 & 0.77 & 0.19 \\
{$[0.78,0.87]$} & {$[0.46,0.79]$} & {$[0.62,0.73]$} & {$[0.44,0.79]$} & {$[0.74,0.81]$} & {$[0.13,0.27]$} \\
$\gamma_{\pi}$ & $\Pi$ & $\rho_{d}$ & $\rho_{\varphi}$ & $\sigma_{A}$ & $\sigma_{d}$ \\
1.29 & 1.010 & 0.12 & 0.93 & -3.97 & -1.51 \\
{$[1.02,1.47]$} & {$[1.008,1.011]$} & {$[0.04,0.22]$} & {$[0.89,0.96]$} & {$[-4.17,-3.78]$} & {$[-1.82,-1.11]$} \\
$\sigma_{\varphi}$ & $\sigma_{\mu}$ & $\sigma_{e}$ & $\Lambda_{\mu}$ & $\Lambda_{A}$ & \\
-2.36 & -5.43 & -5.85 & $3.4 \mathrm{e}-3$ & $2.8 \mathrm{e}-3$ & \\
{$[-2.76,-1.74]$} & {$[-5.52,-5.35]$} & {$[-5.94,-5.74]$} & {$[0.003,0.004]$} & {$[0.002,0.004]$} & \\
\hline
\end{tabular}
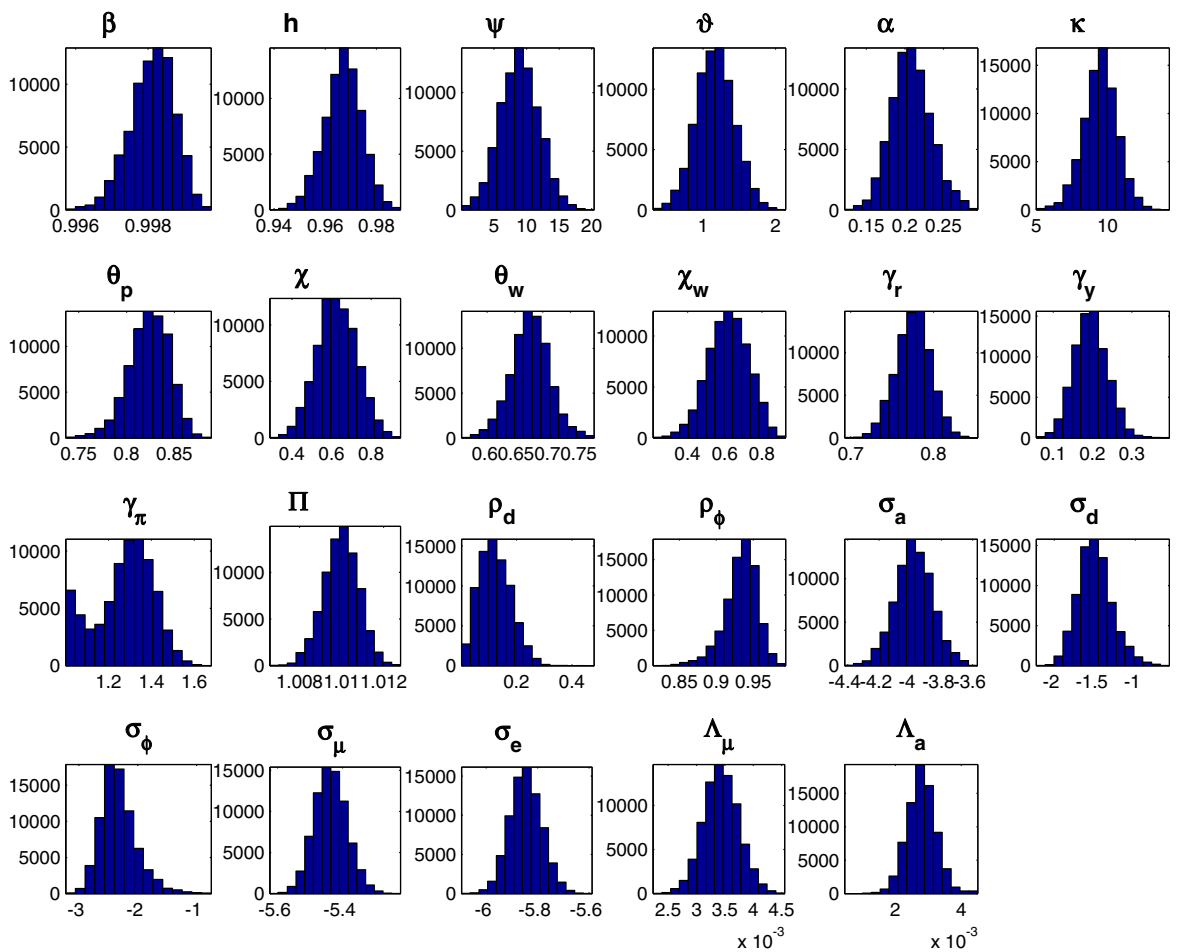

Fig. 1 Posterior distribution, Smets-Wouters priors

What do we learn from our estimates? First, the discount factor $\beta$ is very high, 0.998. This is quite usual in DSGE models, since the likelihood wants to match a low interest rate. Since we have long-run growth in the model, the log utility function generates a relatively high interest rate without the help of any discounting. Second, we have a very high degree of habit, around 0.97 . This is necessary to match the slow response of the economy to shocks as documented by innumerable number of VAR 
exercises. Third, the Frisch elasticity of labor supply is 0.85 (1/1.17). This is a nice surprise, since it is a relatively low number, which makes it quite close to the estimates of the micro literature (in fact, some micro estimates are higher than 0.85!). Since one of the criticisms of DSGE models has traditionally been that they assumed a large Frisch elasticity, our model does not suffer from this problem. ${ }^{22}$

Investment is subject to high adjustment costs, 9.51. Again, this is because we want to match a slow response of investment to shocks. The elasticity of output to capital, 0.21 , is very low but similar to the results by Smets and Wouters (2007). When we interpret this number, we need to remember that, on top of the payments to capital, we have the profits of the intermediate good producers. Since the national income and product accounts lump together both quantities as gross operating surplus, the result is consistent with the evidence on income distribution.

The estimates also reveal a fair amount of nominal rigidities. The Calvo parameter for price adjustment, $\theta_{p}$, is 0.82 (an average five-quarter pricing cycle) and for wages it is 0.68 (an average three-quarter wage cycle). The indexation level for prices, $\chi$, is 0.63 , and the indexation for wages is nearly the same, 0.62 . Despite the fair amount of uncertainty in the posterior (for example, $\chi$ ranges between 0.46 and 0.79 ), the model points out the important role of nominal rigidities. There is, of course, the counterargument that since the only way the model can account for the effects of monetary shocks is through picking up large nominal rigidities, the likelihood takes us to zones with high rigidity. In a model with other channels for monetary policy to play a role (for example, with imperfect common knowledge), the likelihood may prefer less nominal rigidities. In that sense, if the DSGE model is extremely misspecified, our inference may lead us to wrong conclusions.

The estimates for the coefficients of the Taylor rule are in line with the estimates of single equation models (Clarida et al. 2000). The coefficient on inflation, $\gamma_{\pi}=1.29$, shows that the Fed respects the Taylor principle (without entering here into a discussion of whether it did in different subperiods as defended by Lubick and Schorfheide, 2004). The coefficient on output, $\gamma_{y}=0.19$, signals a weak but positive response to the output growth gap. The coefficient on lagged interest rates, $\gamma_{R}=0.77$, indicates a strong desire to smooth the changes on nominal interest rates over time, which has been attributed either to an avoidance of disruptions in the money market or to allow new information about the state of the economy to emerge more fully before a large change in monetary policy is fully passed on. The estimated target inflation is a quarterly $1 \%$, perhaps high by today's standards but in line with the behavior of prices during the whole sample.

The growth rates of the investment-specific technological change, $\Lambda_{\mu}$, and of the neutral technology, $\Lambda_{A}$, are roughly equal. This means that the estimated average growth rate of the U.S. economy in per capita terms, $\left(\Lambda_{A}+\alpha \Lambda_{\mu}\right) /(1-\alpha)$ is $0.43 \%$ per quarter, or $1.7 \%$ annually. Finally, the estimated standard deviations of shocks show an important role for both technological shocks and for preference shocks.

\footnotetext{
22 On the other hand, the model, like all New Keynesian models, requires quite large preference shocks. It is not clear to me that we have made much progress by substituting a high Frisch elasticity for these large shocks.
} 


\section{Areas of future research}

In the next few pages, I will outline some of the potential areas of future research for the formulation and estimation of DSGE models. I do not attempt to map out all existing problems. Beyond being rather foolish, it would take me dozens of pages just to briefly describe some of the open questions I am aware of. I will just talk about three questions I have been thinking about lately: better pricing mechanisms, asset pricing, and more robust inference.

\subsection{Better pricing mechanisms}

In our application, we assumed a simple Calvo pricing mechanism. Unfortunately, the jury is still out regarding how bad a simplification it is to assume that the probability of changing prices (or wages) is fixed and exogenous. Dotsey et al. (1999), in an important paper, argue that state-dependent pricing (firms decide when to change prices given some costs and their states) is not only a more natural setup for thinking about rigidities, but also an environment that may provide very different answers than the basic Calvo pricing, in particular with respect to monetary policy design.

More recently, Bils et al. (2008) have presented compelling evidence that statedependent pricing is also a better description of the data. Bils, Klenow and Malin's paper is a remarkably nice contribution because the mapping between microevidence of price and wages changes and nominal rigidity in the aggregate is particularly subtle. An interesting characteristic of our Calvo pricing mechanism is that all the wages are being changed in every period, some because of reoptimization, some because of indexing. Therefore, strictly speaking, the average duration of wages in this model is one period. In the normal setup, we equate a period with one quarter, which indicates that any lower degree of price changes in the data implies that the model display "excess" price volatility. A researcher must then set up a smart "mousetrap." Bils, Klenow, and Malin find their trap in the reset price inflation that they build from micro CPI data. This reset inflation clearly indicates that Calvo pricing cannot capture many of the features of the micro data and the estimated persistence of shocks. The bad news is, of course, that handling a state-dependent pricing model is rather challenging (we have to track a non-trivial distribution of prices), which limits our ability to estimate it. Being able to write, solve, and estimate DSGE models with better pricing mechanisms is, therefore, a first order of business.

\subsection{Asset pricing}

So far, assets and asset pricing have only made a collateral appearance in our exposition. This is a defect common to much of macroeconomics, where quantities (consumption, investment, hours worked) play a much bigger role than prices. However, if we take seriously the implications of DSGE models for quantities, it is inconsistent not to do the same for prices, in particular asset prices. You cannot believe the result while denying the mechanism: it is through asset prices that the market signals the need to increase or decrease current consumption and, in conjunction with wages, the level 
of hours worked. Furthermore, one of the key questions of modern macroeconomics, the welfare cost of aggregate fluctuation, is, in a precise sense, an exercise in asset pricing. Roughly speaking, a high market price for risk will denote a high welfare cost of aggregate fluctuations and low market price for risk, a low welfare cost.

The plight with asset prices is, of course, that DSGE models do a terrible job at matching them: we cannot account for the risk-free interest rate (Weil 1989), the equity premium (Mehra and Prescott 1985), the excess volatility puzzle, the value premium, the slope of the yield curve, or any other of a long and ever-growing list of related observations (Campbell 2003).

The origin of our concerns is that the stochastic discount factor (SDF) implied by the model does not covariate with observed returns in the correct way (Hansen and Jagannathan 1991). For ease of exposition, let me set $h=0$ (the role of habits will become clearer in a moment) and use the equilibrium condition that individual consumption is equal to aggregate consumption. Then, the SDF $m_{t}$ is:

$$
m_{t}=\beta \frac{c_{t}}{c_{t+1}}=\beta \frac{z_{t} \widetilde{c}_{t}}{z_{t+1} \widetilde{c}_{t+1}}=\beta e^{-\Lambda_{z}-z_{z, t+1}} \frac{\widetilde{c}_{t}}{\widetilde{c}_{t+1}} .
$$

Since (detrended) consumption is rather smooth in the data:

$$
\frac{\widetilde{c_{t}}}{\widetilde{c}_{t+1}} \approx 1
$$

and the variance of $z_{z, t+1}$ is low, we have that $\mathbb{E}_{t} m_{t} \approx \beta e^{-\Lambda_{z}}$ and $\sigma_{t}\left(m_{t}\right)$ is small.

To get a sense of the importance of the first result, we can plug in some reasonable value for the parameters. The annual long-run per capita growth of the U.S. economy between 1865 and 2007 has been around $1.9 \%$. I then set $\Lambda_{z}=0.019$. For the discount factor, I pick $\beta=0.999$, which is even higher than our point estimate in Sect. 5 but which makes my point even stronger. Thus, the gross risk-free real interest rate, $R_{t}$ is equal to:

$$
R_{t}=\left(\mathbb{E}_{t} m_{t}\right)^{-1} \approx \beta^{-1} e^{\Lambda_{z}}=1.02
$$

However, in the data, we find that the risk-free real interest rate has been around $1 \%$ (Campbell 2003). This is, in a nutshell, the risk-free interest rate: even in a context where agents practically do not discount the future and where the elasticity of intertemporal substitution (EIS) is 1 , we create a high interest rate. By lowering $\beta$ or the EIS to more reasonable numbers, we only make the puzzle stronger. The extension of the previous formula for the general constant relative risk aversion utility function is:

$$
R_{t}=\left(\mathbb{E}_{t} m_{t}\right)^{-1} \approx \beta^{-1} e^{\frac{1}{\psi} \Lambda_{z}}
$$

where $\psi$ is the EIS. Even by lowering the EIS to 0.5, we would have that $e^{\frac{1}{\psi} \Lambda_{z}}$ would be around 1.04, which closes the door to any hope of ever matching the risk-free interest rate. 
The second result, $m_{t}$ fluctuates very little, implies that the market price for risk,

$$
\frac{\sigma_{t}\left(m_{t}\right)}{\mathbb{E}_{t} m_{t}}
$$

is also low. But this observation just runs in the completely opposite direction of the equity premium puzzle, where, given historical stock returns, we require a large market price for risk.

How can we fix the behavior of the SDF in a DSGE model? My previous argument relied on three basic components. First, that consumption fluctuates little. Second, that the marginal utility of consumption fluctuates little when consumption changes a small amount, and third, that the pricing of assets is done with the SDF. The first component seems robust. Notwithstanding recent skepticism (Barro 2006), I find little evidence of the large fluctuations in consumption that we would need to make the model work. Even during the Great Depression, the yearly fluctuations were smaller than the total drop in consumption over the whole episode (the number that Barro uses) and they were accompanied by an increase in leisure. Exploring the third component, perhaps with incomplete markets or with bounded rationality, is to venture into a wild territory beyond my current fancy for emotions. My summary dismissals of the first and last argument force me to conclude that marginal utility must, somehow, substantially fluctuate when consumption moves just a little bit.

The standard constant relative risk aversion utility functions just cannot deliver these large fluctuations in marginal utility in general equilibrium. As we raise risk aversion, consumers respond by making their consumption decisions smoother. Indeed, for sufficiently large levels of risk aversion, consumption is so smooth that the market price for risk actually falls (Rouwenhost 1995).

Something we can do is to introduce habits, as I did in the model that I estimated before. Then, the SDF becomes

$$
m_{t}=\beta \frac{d_{t}\left(c_{t+1}-h c_{t}\right)^{-1}-h \beta \mathbb{E}_{t+1} d_{t+2}\left(c_{t+2}-h c_{t+1}\right)^{-1}}{d_{t}\left(c_{t}-h c_{t-1}\right)^{-1}-h \beta \mathbb{E}_{t} d_{t+1}\left(c_{t+1}-h c_{t}\right)^{-1}}
$$

and for a sufficiently high level of $h$, we can obtain large fluctuations of the SDF. The intuition is that, as $h \rightarrow 1$, we care about the ratio of the first differences in consumption and not the ratio of levels, and this ratio of first differences can be quite large. Habits are plausible (after a few trips in business class, coming back to coach is always a tremendous shock) and there may be some good biological reasons why nature has given us a utility function with habits (Becker and Rayo 2007). At the same time, we do not know much about the right way to introduce habits in the utility function (the simple form postulated above is rather arbitrary and rejected by the data, as shown by Chen and Ludvigson 2008) and habits generate interest rates that are too volatile.

Consequently, a second avenue is the exploration of "exotic preferences." Standard expected utility functions, like the one used in this paper, face many theoretical limitations. Without being exhaustive, standard expected utility functions do not capture a preference for the timing of resolution of uncertainty, they do not reflect attitudes toward ambiguity, and they cannot accommodate loss aversion. Moreover, the 
standard model assumes that economic agents do not fear missespecification: they are sure that the model in their heads is the same as the true description of the world. These limitations are potentially of empirical importance as they may be behind our inability to account for many patterns in the data, in particular the puzzling behavior of the prices of many assets and the risk premia (Bansal and Yaron 2004). Over the last several years, economists have paid increasing attention to new forms of the utility function or with fear of misspecification. As a result of this interest, there is a growing excitement about the potentialities of this research area (see the survey by Backus et al. 2005, and the monograph by Hansen and Sargent 2007, for models where the agents want to behave in a way that is robust to misspecification mistakes). However, disappointingly little work has been done in the empirical estimation of DSGE models (or even partial equilibrium models) with this type of preferences (see the review of Hansen et al. 2007). A better and more realistic understanding of utility functions is bound to deliver high yields and this understanding must rely on good econometrics (for some recent attempts, see some of my own work on estimation of models with Esptein-Zin preferences: Binsbergen et al. 2008).

\subsection{More robust inference}

The relative disadvantage of Bayesian methods when dealing with semiparametrics that we discussed in Sect. 3 is unsatisfactory. DSGE models are complex structures. To make the models useful, researchers add many mechanisms that affect the dynamics of the economy: sticky prices, sticky wages, adjustment costs, etc. In addition, DSGE models require many parametric assumptions: the utility function, the production function, the adjustment costs, the distribution of shocks, etc.

Some of those parametric choices are based on restrictions that the data impose on the theory. For example, the observation that labor income share has been relative constant since the 1950s suggests that a Cobb-Douglas production function may not be a bad approximation to reality (although this assumption itself is problematic: see the evidence in Young 2005, among others). Similarly, the observation that the average labor supplied by adults in the U.S. economy has been relatively constant over the last several decades requires a utility function with a marginal rate of substitution between leisure and consumption that is linear in consumption.

Unfortunately, many other parametric assumptions do not have much of an empirical foundation. Instead, researchers choose parametric forms for those functions based only on convenience. For example, in the prototypical DSGE model that we presented in the previous section, the investment adjustment cost function $S(\cdot)$ plays an important role in the dynamics of the economy. However, we do not know much about this function. Even the mild restrictions that we imposed are not necessarily true in the data. ${ }^{23}$ For example, there is much evidence of non-convex adjustment costs at the plant level (Cooper and Haltiwanger 2006) and of non-linear aggregate dynamics

\footnotetext{
23 If we are linearizing the model or computing a second order approximation, we do not need to specify more of the function than those properties. However, if we want to compute arbitrarily high order approximations or use a projection solution method, we will need to specify a full parametric form.
} 
(Caballero and Engel 1999). Similarly, we assume a Gaussian structure for the shocks driving the dynamics of the economy. However, there is much evidence (Geweke 1993, 1994; Fernández-Villaverde and Rubio-Ramírez 2007) that shocks to the economy are better described by distributions with fat tails.

The situation is worrisome. Functional form misspecification may contaminate the whole inference exercise. Moreover, Heckman and Singer (1984) show that the estimates of dynamic models are inconsistent if auxiliary assumptions (in their case, the modeling of individual heterogeneity in duration models) are misspecified. These concerns raise the question of how we can conduct inference that is more robust to auxiliary assumptions, especially within a Bayesian framework.

Researchers need to develop new techniques that allow for the estimation of DSGE models using a Bayesian framework where we can mix tight parametric assumptions along some dimensions while keeping as much flexibility as possible in those aspects of the model that we have less confidence with. The potential benefits from these new methods are huge. Our approach shares many lines of contact with Chen and Ludvigson (2008), a paper that has pioneered the use of more general classes of functions when estimating dynamic equilibrium models within the context of methods of moments. Also, I am intrigued by the possibilities of ideas like those in Álvarez and Jermann (2004), who use data from asset pricing to estimate the welfare cost of the business cycle without the need to specify particular preferences. In a more theoretical perspective, Kimball (2002) has worked out many implications of DSGE models that do not depend on parametric assumptions. Some of these implications are potentially usable for estimation.

\section{Concluding remarks}

I claimed in the introduction that the New Macroeconometrics is a new and exciting area of research. The previous pages, even if brief, have attempted to show the reader why the field is important and how it defines the new gold standard of empirical research in macroeconomics. But there is an even better part of the deal. Much needs to be done in the field: the number of papers I can think about writing in the next decade, both theoretical and applied, is nearly unbounded (and, of course, I can only think about a very small subset of all the possible and interesting papers to write). Since my ability and the ability of other practitioners in the New Macroeconometrics are limited by the tight constraints of time, we need more eager young minds to join us. I hope that some readers will find this call intriguing.

Acknowledgments Much of the research reviewed in this paper was undertaken jointly with Juan Rubio-Ramírez, the best coauthor I could have hoped for. I thank Antonio Cabrales and Pedro Mira for the invitation to deliver the lecture that led to this paper, Wen Yao for research assistance, and the NSF for financial support.

Open Access This article is distributed under the terms of the Creative Commons Attribution Noncommercial License which permits any noncommercial use, distribution, and reproduction in any medium, provided the original author(s) and source are credited. 


\section{References}

Abreu D, Pearce D, Stacchetti E (1990) Toward a theory of discounted repeated games with imperfect monitoring. Econometrica 58:1041-1063

Adolfson M, Laséen S, Lindé J, Villani M (2005) Bayesian estimation of an open economy DSGE model with incomplete pass-through. Sveriges Riksbank Working Paper Series 179

Alesina A, Glaeser E, Sacerdote B (2006) Work and leisure in the U.S. and Europe: why so different? NBER Macroecon Annu 2005:1-64

Álvarez F, Jermann UJ (2004) Using asset prices to measure the cost of the business cycle. J Political Econ 112:1223-1256

Álvarez LJ, Burriel P, Hernando I (2005) Do decreasing hazard functions for price changes make sense? Working Paper No. 461, European Central Bank

An S, Schorfheide F (2006) Bayesian analysis of DSGE models. Econom Rev 26:113-172

Andrés J, Burriel P, Estrada A (2006) BEMOD: a DSGE model for the Spanish economy and the rest of the Euro area. Documento de Trabajo del Banco de España 0631

Aruoba SB, Fernández-Villaverde J, Rubio-Ramírez J (2006) Comparing solution methods for dynamic equilibrium economies. J Econ Dyn Control 30:2477-2508

Arulampalam AS, Maskell S, Gordon N, Clapp T (2002) A tutorial on particle filters for online nonlinear/Non-Gaussian Bayesian tracking. IEEE Trans Signal Process 50:174-188

Backus DK, Kehoe P, Kydland F (1992) International real business cycles. J Political Econ 100:745-775

Backus DK, Kehoe P, Kydland F (1995) International business cycles: theory and evidence. In: Cooley T (ed) Frontiers of business cycle research. Princeton University Press, Princeton

Backus DK, Routledge BR, Zin SE (2005) Exotic preferences for macroeconomists. NBER Macroecon Annu 2004:319-390

Bansal R, Yaron A (2004) Risks for the long run: a potential resolution of asset pricing puzzles. J Finance 59:1481-1509

Barro (2006) On the welfare costs of consumption uncertainty. NBER Working Paper 12763

Becker GS, Rayo L (2007) Habits, peers, and happiness: an evolutionary perspective. Am Econ Rev Pap Proc 97:487-491

Benhabib J, Farmer RE (1992) Indeterminacy and increasing returns. J Econ Theory 63:19-41

Benhabib J, Rogerson R, Wright R (1991) Homework in macroeconomics: household production and aggregate fluctuations. J Political Econ 99:1166-1187

Berger JO, Wolpert RL (1988) The likelihood principle, 2nd edn. The Institute of Mathematical Statistics

Bernanke BS, Gertler M, Gilchrist S (1999) The financial accelerator in a quantitative business cycle framework. In: Taylor JB, Woodford M (eds) Handbook of macroeconomics, vol 1, pp 1341-1393. North-Holland/Elsevier, New York

Bernardo JM, Smith AFM (2000) Bayesian theory. Wiley Series in Probability and Statistics, New York

Bils M, Klenow P (2004) Some evidence on the importance of sticky prices. J Political Econ 112:947-985

Bils M, Klenow PJ, Malin BA (2008) Reset price inflation and the impact of monetary policy shocks. Mimeo, University of Rochester

Binsbergen JH, Fernández-Villaverde J, Koijen RSJ, Rubio-Ramirez J (2008) Working with Epstein-Zin preferences: computation and likelihood estimation of DSGE models with recursive preferences. Mimeo, University of Pennsylvania

Birnbaum A (1962) On the foundations of statistical inference. J Am Stat Assoc 57:269-326

Blanchard OJ, Kiyotaki N (1987) Monopolistic competition and the effects of aggregate demand. Am Econ Rev 77:647-666

Boivin J, Giannoni M (2006) DSGE models in a data-rich environment. NBER Working Paper, 12272

Browning M, Hansen LP, Heckman JJ (1999) Micro data and general equilibrium models. In: Taylor JB, Woodford M (eds) Handbook of macroeconomics, vol 1, chap 8, pp 543-633. Elsevier, Amsterdam

Caballero RJ, Engel EMRA (1999) Explaining investment dynamics in U.S. manufacturing: a generalized (S,s) approach. Econometrica 67:783-826

Calvo GA (1983) Staggered prices in a utility-maximizing framework. J Monet Econ 12:383-398

Campbell JY (2003) Consumption-based asset pricing. In: Constantinides GM, Harris M, Stulz RM (eds) Handbook of the economics of finance, 1st edn, vol 1, chap 13. pp 803-887, Elsevier, Amsterdam

Canova F (2007) Methods for applied macroeconomics research. Princeton University Press, Princeton

Canova F (2008) Bridging cyclical DSGE Models and the raw data. Mimeo, Pompeu Fabra University 
Canova F, Ferroni F (2009) Multiple filtering devices for the estimation of cyclical DSGE models. Mimeo, Pompeu Fabra University

Canova F, Sala L (2006) Back to square one: identification issues in DSGE models. Mimeo, Pompeu Fabra University

Caplin A, Leahy J (1991) State-dependent pricing and the dynamics of money and output. Q J Econ 106: 683-708

Caplin A, Leahy J (1997) Aggregation and optimization with state-dependent pricing. Econometrica 65:601-626

Caplin A, Spulber D (1987) Menu costs and the neutrality of money. Q J Econ 102:703-725

Chamberlain G, Imbens GW (2003) Nonparametric applications of Bayesian inference. J Bus Econ Stat 21:12-18

Chen XH, Ludvigson SC (2008) Land of addicts? An empirical investigation of habit-based asset pricing models. J Appl Econom 24(7):1057-1093

Chernozhukov V, Hong H (2003) A MCMC approach to classical estimation. J Econom 115(2):293-346

Christiano LJ (1990) Linear-quadratic approximation and value-function iteration: a comparison. J Bus Econ Stat 8:99-113

Christiano L, Eichenbaum M, Evans CL (2005) Nominal rigidities and the dynamic effects of a shock to monetary policy. J Political Econ 113:1-45

Christoffel K, Coenen G, Warne A (2007) The new area-wide model of the Euro area: specification and first estimation results. Mimeo, European Central Bank

Clarida R, Galí J, Gertler M (2000) Monetary policy rules and macroeconomic stability: evidence and some theory. Q J Econ 115:147-180

Cooper RW (2002) Estimation and identification of structural parameters in the presence of multiple equilibria. Ann Econ Stat 6:1-25

Cooper RW, Haltiwanger JC (2006) On the nature of capital adjustment costs. Rev Econ Stud 73:611-633

Correia I, Neves J, Rebelo S (1995) Business cycles in small open economies. Eur Econ Rev 39:1089-1113

DeJong DN, Dave C (2007) Structural macroeconometrics. Princeton University Press, Princeton

Del Moral P, Jacod J (2002) The Monte-Carlo method for filtering with discrete time observations. Central limit theorems. In: Lyons TJ, Salisbury TS (eds) Numerical methods and stochastics. The Fields Institute Communications, American Mathematical Society, Providence

Del Negro M, Schorfheide F (2008) Forming priors for DSGE models (and how it affects the assessment of nominal rigidities). J Monet Econ 55:1191-1208

Dhyne E, Álvarez LJ, Bihan HL, Veronese G, Dias D, Hoffmann J, Jonker N, Lunnemann P, Rumler F, Vilmunen J (2006) Price setting in the Euro area and the United States: some facts from individual consumer price data. J Econ Perspectives 20:171-192

Dotsey M, King RG, Wolman A (1999) State dependent pricing and the general equilibrium dynamics of money and output. Q J Econ 114:655-690

Doucet A, de Freitas N, Gordon N (2001) Sequential Monte Carlo methods in practice. Springer, Berlin

Edge RM, Kiley MT, Laforte J-P (2009) A comparison of forecast performance between Federal Reserve staff forecasts, simple reduced-form models, and a DSGE model. Finance and Economics Discussion Series 2009-10, Board of Governors of the Federal Reserve System

Epstein L, Zin SE (1989) Substitution, risk aversion, and the temporal behavior of consumption and asset returns: a theoretical framework. Econometrica 57:937-969

Epstein L, Zin SE (1991) Substitution, risk aversion, and the temporal behavior of consumption and asset returns: an empirical analysis. J Political Econ 99:263-286

Erceg CJ, Guerrieri L, Gust C (2006) SIGMA: a new open economy model for policy analysis. Int J Central Banking 2:1-50

Farmer RE (2007) Aggregate demand and supply. NBER Working Paper, 13406

Farmer RE, Waggoner DF, Zha T (2006a) Minimal state variable solutions to Markov-switching rational expectations models. Mimeo, Federal Reserve Bank of Atlanta

Farmer RE, Waggoner DF, Zha T (2006b) Indeterminacy in a forward looking regime switching model. Mimeo, Federal Reserve Bank of Atlanta

Fernández-Villaverde J, Rubio-Ramírez J (2004) Comparing dynamic equilibrium models to data: a Bayesian approach. J Econom 123:153-187

Fernández-Villaverde J, Rubio-Ramírez J (2005) Estimating dynamic equilibrium economies: linear versus nonlinear likelihood. J Appl Econom 20:891-910

Fernández-Villaverde J, Rubio-Ramirez J (2006) Solving DSGE models with perturbation methods and a change of variables. J Econ Dyn Control 30:2509-2531 
Fernández-Villaverde J, Rubio-Ramírez J (2007) Estimating macroeconomic models: a likelihood approach. Rev Econ Stud 74:1059-1087

Fernández-Villaverde J, Rubio-Ramirez J (2008) How structural are structural parameters?. NBER Macroecon Annu 2007:83-137

Fernández-Villaverde J, Rubio-Ramírez J, Santos MS (2006) Convergence properties of the likelihood of computed dynamic models. Econometrica 74:93-119

Fernández-Villaverde J, Guerrón-Quintana P, Rubio-Ramírez J (2008) The new macroeconometrics: a Bayesian approach. In: O'Hagan A, West M (eds) Handbook of applied bayesian analysis. Oxford University Press, New York

Fisher J (2006) The dynamic effects of neutral and investment-specific technology shocks. J Political Econ $114: 413-452$

Freedman DA (1963) On the asymptotic behavior of Bayes estimates in the discrete case. Ann Math Stat $34: 1386-1403$

Friedman M, Schwartz AJ (1971) A monetary history of the United States, 1867-1960. Princeton University Press, Princeton

Galeson D (2007) Old masters and young geniuses: the two life cycles of artistic creativity. Princeton University Press, Princeton

Geweke JF (1993) Bayesian treatment of the independent student-t linear model. J Appl Econom 8:S19-S40

Geweke JF (1994) Priors for macroeconomic time series and their application. Econom Theory 10:609-632

Geweke JF (1998) Using simulation methods for Bayesian econometric models: inference, development and communication. Staff Report, 249, Federal Reserve Bak of Minneapolis

Ghosh JK, Ramamoorthi RV (2003) Bayesian nonparametrics. Springer, Berlin

Griffiths TL, Tenenbaum JB (2006) Optimal predictions in everyday cognition. Psychol Sci 17:767-773

Greenwood J, Herkowitz Z, Krusell P (1997) Long-run implications of investment-specific technological change. Am Econ Rev 87:342-362

Greenwood J, Herkowitz Z, Krusell P (2000) The role of investment-specific technological change in the business cycle. Eur Econ Rev 44:91-115

Guerrón-Quintana P (2008) What you match does matter: the effects of data on DSGE estimation. Mimeo, North Carolina State University

Hall R (1997) Macroeconomic fluctuations and the allocation of time. J Labor Econ 15:S223-S250

Hansen LP, Jagannathan R (1991) Implications of security market data for models of dynamic economies. J Political Econ 99:225-262

Hansen LP, Sargent TJ (1993) Seasonality and approximation errors in rational expectations models. J Econom 55:21-55

Hansen LP, Sargent TJ (2007) Robustness. Princeton University Press, Princeton

Hansen LP, Heaton J, Lee J, Roussanov N (2007) Intertemporal substitution and risk aversion. In: Heckman JJ, Leamer E (eds) Handbook of econometrics, vol 6, pp 3967-4056. North-Holland/ Elsevier, New York

Harrison R, Nikolov K, Quinn M, Ramsay G, Scott A, Thomas R (2005) The Bank of England quarterly model. Bank of England

Harvey AC (1989) Forecasting, structural time series models and the Kalman Filter. Cambridge University Press, Cambridge

Heckman J, Singer B (1984) A method for minimizing the impact of distributional assumptions in econometric models of duration data. Econometrica 68:839-874

Jovanovic B (1989) Observable implications of models with multiplicity of equilibria. Econometrica 57:1431-1436

Judd KL (1998) Numerical methods in economics. MIT Press, Cambridge

Judd KL, Guu SM (1993) Perturbation solution methods for economic growth model. In: Varian H (ed) Economic and financial modelling in mathematica. Springer, Berlin

Justiniano A, Primiceri GE (2008) The time varying volatility of macroeconomic fluctuations. Am Econ Rev 98:604-641

Keynes JM (1936) The general theory of employment, interest, and money. MacMillan, New York

Kilponen J, Ripatti A (2006) Introduction to AINO. Mimeo, Bank of Findland

Kim J (1998) Large sample properties of posterior densities, Bayesian information criterion and the likelihood principle in nonstationary time series models. Econometrica 66:359-380

Kim C, Nelson CR (1998) Has the U.S. economy become more stable? A Bayesian approach based on a Markov-switching model of the business cycle. Rev Econ Stat 81:608-616

Kimball MS (2002) Real business cycle theory: a semiparametric approach. Mimeo, University of Michigan 
King RG, Plosser CI, Rebelo ST (2002) Production, growth and business cycles: technical appendix. Comput Econ 20:87-116

King RG, Plosser CI, Stock JH, Watson MW (1991) Stochastic trends and economic fluctuations. Am Econ Rev 81:819-840

Kitamura Y, Stutzer M (1997) An information-theoretic alternative to generalized method of moment estimation. Econometrica 65:861-874

Klenow PJ, Kryvtsov O (2008) State-dependent or time-dependent pricing: does it matter for recent US inflation? Q J Econ 123:863-904

Komunjer I, Ng S (2009a) Dynamic indentification of DSGE models. Mimeo, Columbia University

Komunjer I, Ng S (2009b) Issues in static indentification of DSGE models. Mimeo, Columbia University

Kortelainen M (2002) Edge: a model of the Euro area with applications to monetary policy. Bank of Finland Studies E:23-2002, Bank of Finland

Künsch HR (2005) Recursive Monte Carlo filters: algorithms and theoretical analysis. Ann Stat 33: 1983-2021

Kydland FE, Prescott EC (1982) Time to build and aggregate fluctuations. Econometrica 50:1345-1370

Lagos R, Wright R (2005) A unified framework for monetary theory and monetary analysis. J Political Econ 113:463-484

Lubick T, Schorfheide F (2004) Testing for indeterminacy: an application to U.S. monetary policy. Am Econ Rev 94:190-217

Lucas R (1972) Expectations and the neutrality of money. J Econ Theory 4(2):103-124

Mankiw GN, Reis R (2002) Sticky information versus sticky prices: a proposal to replace the new Keynesian Phillips curve. Q J Econ 117:1295-1328

Manski CF (1999) Identification problems in the social sciences. Harvard University Press, Cambridge

McConnell MM, Pérez-Quirós G (2000) Output fluctuations in the United States: what has changed since the early 1980's? Am Econ Rev 90:1464-1476

McFadden DL (1989) A method of simulated moments for estimation of discrete response models without numerical integration. Econometrica 57:995-1026

Mehra R, Prescott EC (1985) The equity premium: a puzzle. J Monet Econ 15:145-161

Mendoza E (1991) Real business cycles in a small open economy. Am Econ Rev 81:797-818

Mendoza E (1995) The terms of trade, the real exchange rate, and economic fluctuations. Int Econ Rev 36:101-137

Mengersen KL, Robert CP, Guihenneuc-Jouyaux C (1999) MCMC convergence diagnostics: a 'review'. In: Bernardo JM, Berger JO, Dawid AP, Smith AFM (eds) Bayesian statistics 6. Oxford Sciences Publications, New York

Monfort A (1996) A reappraisal of misspecified econometric models. Econom Theory 12:597-619

Murchison S, Rennison A (2006) ToTEM: the Bank of Canada's New Canadian projection model. Bank of Canada Technical Report, Bank of Canada

Nakamura E, Steinsson J (2008) Five facts about prices: a reevaluation of menu cost models. Q J Econ 123:1415-1464

O’Hagan A, West M (eds) (2009) Handbook of applied Bayesian analysis. Oxford University Press, New York

Orphanides A (2002) Monetary policy rules and the great inflation. Am Econ Rev 92:115-120

Owen AR (2001) Empirical likelihood. Chapman \& Hall/CRC, London

Pakes A, Pollard D (1989) Simulation and the asymptotics of optimization estimators. Econometrica 57:1027-1057

Phillips PCB (1996) Econometric model determination. Econometrica 64:763-812

Phillips PCB, Ploberger W (1996) An asymptotic theory of Bayesian inference for time series. Econometrica 64:381-412

Ragusa G (2006) Bayesian likelihoods for moment condition models. Mimeo, UC-Irvine

Rissanen J (1986) Stochastic complexity and modeling. Ann Stat 14:1080-1100

Robert CP (2001) The Bayesian choice, 2nd edn. Springer, Berlin

Robert CP, Casella G (2005) Monte Carlo statistical methods, 2nd edn. Springer, Berlin

Roberts G, Gelman A, Gilks W (1997) Weak convergence and optimal scaling of random walk metropolis algorthims. Ann Appl Probab 7:110-120

Robins JM, Ritov Y (1997) Toward a curse of dimensionality appropriate (CODA) asymptotic theory for semi-parametric models. Stat Med 16:285-319 
Rogerson R, Wallenius J (2007) Micro and macro elasticities in a life cycle model with taxes. NBER Working Paper, 13017

Rouwenhost KG (1995) Asset pricing implications of equilibrium business cycle models. In: Cooley TF (ed) Frontiers of business cycle research. Princeton University Press, Princeton

Rubin DB (1988) Using the SIR algorithm to simulate posterior distributions. In: Bernardo JM, DeGroot MH, Lindley DV, Smith AFM (eds) Bayesian statistics 3, pp 395-402. Oxford University Press, New York

Schennach SM (2005) Bayesian exponentially tilted empirical likeliood. Biometrika 92:31-46

Schmitt-Grohé S, Uribe M (2004) Solving dynamic general equilibrium models using a second-order approximation to the policy function. J Econ Dyn Control 28:755-775

Sims CA (2002) Implications of rational inattention. Mimeo, Princeton University

Sims CA, Uhlig H (1991) Understanding unit rooters: a helicopter tour. Econometrica 59:1591-1599

Sims CA, Zha T (2006) Were there regime switches in U.S. monetary policy? Am Econ Rev 96:54-81

Smets F, Wouters R (2007) Shocks and frictions in US business cycles: a Bayesian DSGE approach. Am Econ Rev 97:586-606

Stengel RF (1994) Optimal control and estimation. Dover, New York

Stock JH, Watson MW (2003) Has the business cycle changed, and why? NBER Macroecon Annu 2002:159-218

Stokey NL, Lucas RE, Prescott EC (1989) Recursive methods in economic dynamics. Harvard University Press, Cambridge

Wallace N (2001) Whither monetary economics? Int Econ Rev 42:847-869

Weil P (1989) The equity premium puzzle and the risk-free rate puzzle. J Monet Econ 24:401-421

Woodford MD (2003) Interest and prices. Princeton University Press, Princeton

Young (2005) One of the things that we know that ain't so: why U.S. labor share is not relatively stable. Mimeo, University of Mississippi

Zellner A (1988) Optimal information processing and Bayes' theorem. Am Stat 42:278-284 